\title{
Lead: properties, history, and applications
}

Mikhail Boldyrev*, et al.

\begin{abstract}
Lead is a chemical element with the atomic number 82 and the symbol $\mathbf{P b}$ (from the Latin plumbum). It is a heavy metal that is denser than most common materials. Lead is soft and malleable, and has a relatively low melting point. When freshly cut, lead is silvery with a hint of blue; it tarnishes to a dull gray color when exposed to air. Lead has the highest atomic number of any stable element and concludes three major decay chains of heavier elements.

Lead is a relatively unreactive post-transition metal. Its weak metallic character is illustrated by its amphoteric nature; lead and its oxides react with acids and bases, and it tends to form covalent bonds. Compounds of lead are usually found in the +2 oxidation state rather than the +4 state common with lighter members of the carbon group. Exceptions are mostly limited to organolead compounds. Like the lighter members of the group, lead tends to bond with itself; it can form chains, rings and polyhedral structures.

Lead is easily extracted from its ores; prehistoric people in Western Asia knew of it. Galena, a principal ore of lead, often bears silver, interest in which helped initiate widespread extraction and use of lead in ancient Rome. Lead production declined after the fall of Rome and did not reach comparable levels until the Industrial Revolution. In 2014, annual global production of lead was about ten million tonnes, over half of which was from recycling. Lead's high density, low melting point, ductility, and relative inertness to oxidation make it useful. These properties, combined with its relative abundance and low cost, resulted in its extensive use in construction, plumbing, batteries, bullets and shot, weights, solders, pewters, fusible alloys, white paints, leaded gasoline, and radiation shielding.

In the late 19th century, lead's toxicity was recognized, and its use has since been phased out of many applications. Lead is a toxin that accumulates in soft tissues and bones, it acts as a neurotoxin damaging the nervous system and interferences with the function of biological enzymes. It is particularly problematic in children: even if blood levels are promptly normalized with treatment, neurological disorders, such as brain damage and behavioral problems, may result
\end{abstract}

\section{Physical properties}

\section{Atomic \\ A lead atom has 82 electrons, arranged in an electron configuration of $\left[X e 4^{1} \mathrm{f}^{14} 5 \mathrm{~d}^{10} 6 \mathrm{~s}^{2} 6 \mathrm{p}^{2}\right.$. The combined first and second ionization energies-the total energy re- quired to remove the two $6 \mathrm{p}$ electrons-is close to that of tin, lead's upper neighbor in the carbon group. This is unusual; ionization energies generally fall going down a group, as an element's outer electrons become more distant from the nucleus, and more shielded by smaller orbitals. The similarity of ionization energies is caused by the lanthanide contraction-the decrease in element \\ ${ }^{1}$ Department of Optimal Control, Faculty of Computational Mathe- matics and Cybernetics, Moscow State University, Moscow, Russia \\ *Author correspondence: r8rgtrs@gmail.com \\ ORCID: [0000-0000-0000-0001] \\ Licensed under: CC-BY-SA \\ Received 22-11-2017; accepted 03-07-2018}

radii from lanthanum (atomic number 57 ) to lutetium (71), and the relatively small radii of the elements after hafnium (72). This is due to poor shielding of the nucleus by the lanthanide $4 \mathrm{f}$ electrons. The combined first four ionization energies of lead exceed those of tin, ${ }^{[1]}$ contrary to what periodic trends would predict. Relativistic effects, which become significant in heavier atoms, contribute to this behavior. ${ }^{[a]}$ One such effect is the inert pair effect: the 6 s electrons of lead become reluctant to participate in bonding, which leads to elevated ionization energies and makes the distance between nearest atoms in crystalline lead unusually long. ${ }^{[3]}$

Lead's lighter carbon group congeners form stable or metastable allotropes with the tetrahedrally coordinated and covalently bonded diamond cubic structure. The energy levels of their outer $s$ - and $p$-orbitals are close enough to allow mixing into four hybrid $\mathrm{sp}^{3}$ orbitals. In lead, the inert pair effect increases the separation between its s- and p-orbitals, and the gap cannot be 
overcome by the energy that would be released by extra bonds following hybridization. ${ }^{[4]}$ Rather than having a diamond cubic structure, lead forms metallic bonds in which only the p-electrons are delocalized and shared between the $\mathrm{Pb}^{2+}$ ions. Lead consequently has a facecentered cubic structure ${ }^{[5]}$ like the similarly sized ${ }^{[6]}$ divalent metals calcium and strontium. ${ }^{[7][b][c][d]}$

\section{Bulk}

Pure lead has a bright, silvery appearance with a hint of blue. ${ }^{[12]}$ It tarnishes on contact with moist air, and takes on a dull appearance the hue of which depends on the prevailing conditions. Characteristic properties of lead include high density, malleability, ductility, ${ }^{\left[{ }^{[e]}\right.}$ and high resistance to corrosion due to passivation. ${ }^{[13]}$

Lead's close-packed face-centered cubic structure and high atomic weight result in a density ${ }^{[15]}$ of $11.34 \mathrm{~g} / \mathrm{cm}^{3}$, which is greater than that of common metals such as iron $\left(7.87 \mathrm{~g} / \mathrm{cm}^{3}\right)$, copper $\left(8.93 \mathrm{~g} / \mathrm{cm}^{3}\right)$, and zinc $(7.14$ $\left.\mathrm{g} / \mathrm{cm}^{3}\right)^{[16]}$ This density is the origin of the idiom to go over like a lead balloon. ${ }^{[17][18][f]}$ Some rarer metals are denser: tungsten and gold are both at $19.3 \mathrm{~g} / \mathrm{cm}^{3}$, and osmium - the densest metal known-has a density of $22.59 \mathrm{~g} / \mathrm{cm}^{3}$, almost twice that of lead. ${ }^{[19]}$

Lead is a very soft metal with a Mohs hardness of 1.5 ; it can be scratched with a fingernail. ${ }^{[20]}$ It is very malleable and quite ductile. ${ }^{[21]}$ The bulk modulus of lead-a measure of its ease of compressibility-is $45.8 \mathrm{GPa}$. In comparison, that of aluminium is $75.2 \mathrm{GPa}$; copper 137.8 $\mathrm{GPa}$; and mild steel 160-169 GPa. ${ }^{[22]}$ Lead's tensile strength, at $12-17 \mathrm{MPa}$, is low (that of aluminium is 6 times higher, copper 10 times, and mild steel 15 times higher); it can be strengthened by adding small amounts of copper or antimony. ${ }^{[23]}$

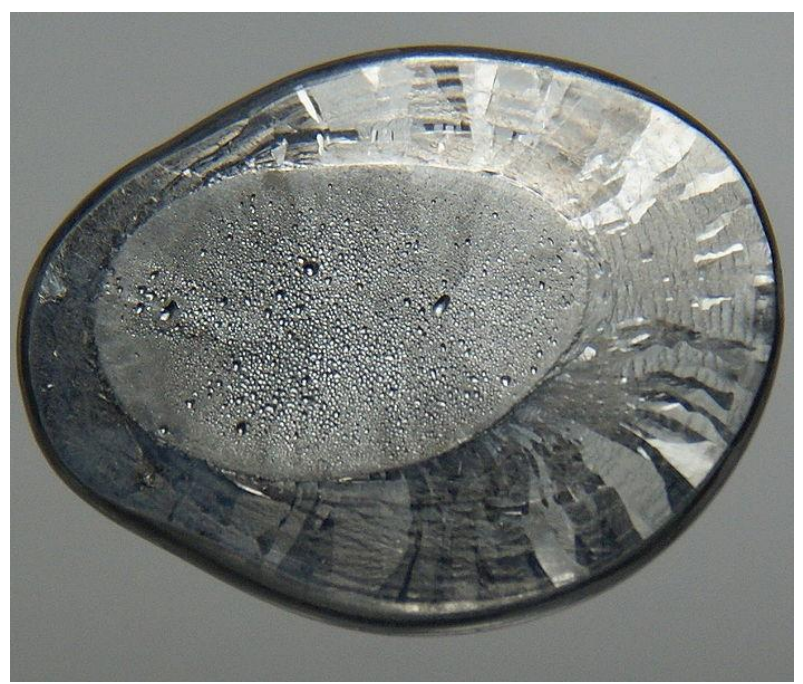

Figure 1 | A sample of lead solidified from the molten state. Juergen Kummer, CC-BY 3.0
The melting point of lead-at $327.5^{\circ} \mathrm{C}\left(621.5^{\circ} \mathrm{F}\right)^{[24]}$-is very low compared to most metals. ${ }^{[15][g]}$ Its boiling point of $1749^{\circ} \mathrm{C}\left(3180^{\circ} \mathrm{F}\right)^{[24]}$ is the lowest among the carbon group elements. The electrical resistivity of lead at 20 ${ }^{\circ} \mathrm{C}$ is 192 nanoohm-meters, almost an order of magnitude higher than those of other industrial metals (copper at $15.43 \mathrm{n} \Omega \cdot \mathrm{m}$; gold $20.51 \mathrm{n} \Omega \cdot \mathrm{m}$; and aluminium at $24.15 \mathrm{n} \Omega \cdot \mathrm{m}) .{ }^{[26]}$ Lead is a superconductor at temperatures lower than $7.19 \mathrm{~K}_{i}^{[27]}$ this is the highest critical temperature of all type-I superconductors and the third highest of the elemental superconductors. ${ }^{[28]}$

\section{Isotopes}

Natural lead consists of four stable isotopes with mass numbers of 204,206,207, and 208, ${ }^{[29]}$ and traces of five short-lived radioisotopes. ${ }^{[30]}$ The main isotopes of lead, with information on percent abundance, half-life, and decay mode and product, are listed in Table 1 . The high number of isotopes is consistent with lead's atomic number being even. ${ }^{[\mathrm{h}]}$ Lead has a magic number of protons (82), for which the nuclear shell model accurately predicts an especially stable nucleus. ${ }^{[31]}$ Lead-208 has 126 neutrons, another magic number, which may explain why lead-208 is extraordinarily stable. ${ }^{[31]}$

With its high atomic number, lead is the heaviest element whose natural isotopes are regarded as stable; lead-208 is the heaviest stable nucleus. This title was formerly held by bismuth, with an atomic number of 83 , until its only primordial isotope, bismuth-209, was found in 2003 to decay very slowly. ${ }^{[i]}$ The four stable isotopes of lead could theoretically undergo alpha decay to isotopes of mercurywith a release of energy, but this has not been observed for any of them; their predicted half-lives range from $10^{35}$ to $10^{189}$ years. ${ }^{[34]}$

Three of the stable isotopes are found in three of the four major decay chains: lead-206, lead-207, and lead208 are the final decay products of uranium-238, uranium-235, and thorium-232, respectively. These decay

\begin{tabular}{lllll}
\hline & \multicolumn{2}{c}{ Isotope } & \multicolumn{2}{c}{ Decay } \\
\hline & abundance & \multicolumn{1}{c}{ half-life $\left(t_{1 / 2}\right)$} & mode & product \\
\hline${ }^{202} \mathrm{~Pb}$ & syn & $5.25(28) \times 10^{4} \mathrm{y}$ & $\varepsilon$ & ${ }^{202} \mathrm{Tl}$ \\
${ }^{204} \mathrm{~Pb}$ & $1.4 \%$ & stable & & \\
${ }^{205} \mathrm{~Pb}$ & trace & $1.53(7) \times 10^{7} \mathrm{y}$ & $\varepsilon$ & ${ }^{205} \mathrm{Tl}$ \\
${ }^{206} \mathrm{~Pb}$ & $24.1 \%$ & stable & & \\
${ }^{207} \mathrm{~Pb}$ & $22.1 \%$ & stable & & \\
${ }^{208} \mathrm{~Pb}$ & $52.4 \%$ & stable & & \\
${ }^{209} \mathrm{~Pb}$ & trace & $3.253(14) \mathrm{h}$ & $\beta^{-}$ & ${ }^{209} \mathrm{Bi}$ \\
${ }^{210} \mathrm{~Pb}$ & trace & $22.3(22) \mathrm{y}$ & $\beta^{-}$ & ${ }^{210} \mathrm{Bi}$ \\
${ }^{211} \mathrm{~Pb}$ & trace & $36.1(2) \mathrm{min}$ & $\beta^{-}$ & ${ }^{211} \mathrm{Bi}$ \\
${ }^{212} \mathrm{~Pb}$ & trace & $10.64(1) \mathrm{h}$ & $\beta^{-}$ & ${ }^{212} \mathrm{Bi}$ \\
${ }^{214} \mathrm{~Pb}$ & trace & $26.8(9) \mathrm{min}$ & $\beta^{-}$ & ${ }^{214} \mathrm{Bi}$ \\
\hline
\end{tabular}

Table 1 | Main isotopes of lead. Isotopic abundances vary greatly by sample. Standard atomic weight: 207.2(1) ${ }^{[14]}$ $\left(A_{r, \text { standard }}\right)$ 


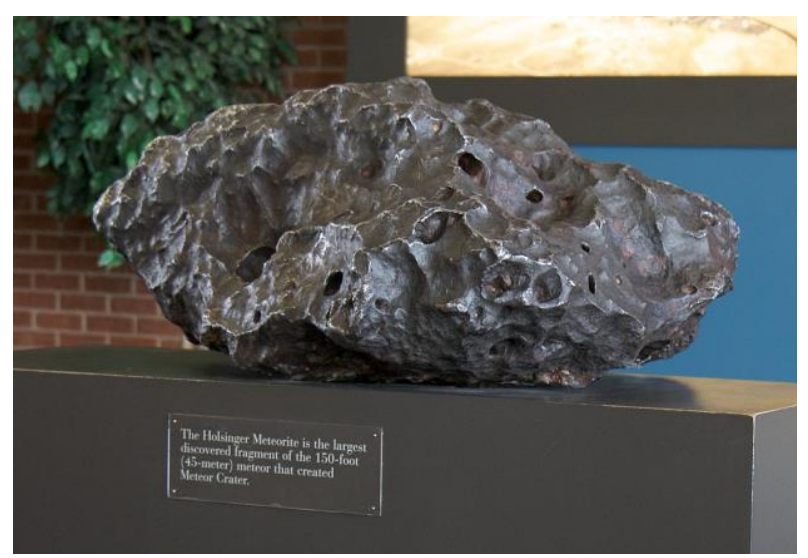

Figure 2 | The Holsinger meteorite, the largest piece of the Canyon Diablo meteorite. Uranium-lead dating and leadlead dating on this meteorite allowed refinement of the age of the Earth to 4.55 billion \pm 70 million years.

Marcin Wichary, CC-BY 2.0

chains are called the uranium chain, the actinium chain, and the thorium chain. ${ }^{[35]}$ Their isotopic concentrations in a natural rock sample depends greatly on the presence of these three parent uranium and thorium isotopes. For example, the relative abundance of lead-208 can range from $52 \%$ in normal samples to $90 \%$ in thorium ores; ${ }^{[36]}$ for this reason, the standard atomic weight of lead is given to only one decimal place. ${ }^{[37]}$ As time passes, the ratios of lead-206 and lead-207 to lead204 increase, since the former two are supplemented by radioactive decay of heavier elements while the latter is not; analysis of lead-207/lead-204 ratios versus lead-206/lead-204 ratios constitutes lead-lead dating. As uranium decays into lead, their relative amounts change; analysis of uranium-238/lead-206 ratios versus uranium-235/lead-207 ratios constitutes uranium-lead dating. ${ }^{[38]}$ Lead-207 exhibits nuclear magnetic resonance, a property that has been used to study its compounds in solution and solid state, ${ }^{[39][40]}$ including in human body. ${ }^{[41]}$

Apart from the stable isotopes, which make up almost all lead that exists naturally, there are trace quantities of a few radioactive isotopes. One of them is lead-210; although it has a half-life of only 22.3 years, ${ }^{[29]}$ small quantities occur in nature because lead-210 is produced by a long decay series that starts with uranium-238 (which has been present for billions of years on Earth). Lead-211, -212, and -214 are present in the decay chains of uranium-235, thorium-232, and uranium-238, respectively, so traces of all three of these lead isotopes are found naturally. Minute traces of lead-209 arise from the very rare cluster decay of radium-223, one of the daughter products of natural uranium-235. Lead-210 is particularly useful for helping to identify the ages of samples by measuring its ratio to lead-206 (both isotopes are present in a single decay chain). ${ }^{[42]}$

In total, 43 lead isotopes have been synthesized, with mass numbers $178-220 .{ }^{[29]}$ Lead-205 is the most stable radioisotope, with a half-life of around $1.5 \times 10^{7}$ years. ${ }^{[j]}$ The second-most stable is lead-202, which has a halflife of about 53,000 years, longer than any of the natural trace radioisotopes. ${ }^{[29]}$

\section{Chemistry}

Bulk lead exposed to moist air forms a protective layer of varying composition. Lead(II) carbonate is a common constituent; ${ }^{[44][45][46]}$ the sulfate or chloride may also be present in urban or maritime settings. ${ }^{[47]}$ This layer makes bulk lead effectively chemically inert in the air. ${ }^{[47]}$ Finely powdered lead, as with many metals, is pyrophoric, ${ }^{[48]}$ and burns with a bluish-white flame. ${ }^{[49]}$

Fluorine reacts with lead at room temperature, forming lead(II) fluoride. The reaction with chlorine is similar but requires heating, as the resulting chloride layer diminishes the reactivity of the elements. ${ }^{[47]}$ Molten lead reacts with the chalcogensto give lead(II) chalcogenides. ${ }^{[50]}$

Lead metal resists sulfuric and phosphoric acid but not hydrochloric or nitric acid; the outcome depends on solubility and subsequent passivation of the product salt. ${ }^{[51]}$ Organic acids, such as acetic acid, dissolve lead in the presence of oxygen. ${ }^{[47]}$ Concentrated alkalis will dissolve lead and form plumbites. ${ }^{[52]}$

\section{Inorganic compounds}

Lead shows two main oxidation states: +4 and +2 . The tetravalent state is common for the carbon group. The divalent state is rare for carbon and silicon, minor for germanium, important (but not prevailing) for tin, and is the more important of the two oxidation states for lead. ${ }^{[47]}$ This is attributable to relativistic effects, specifically the inert pair effect, which manifests itself when there is a large difference in electronegativity between lead and oxide, halide, or nitride anions, leading to a significant partial positive charge on lead.

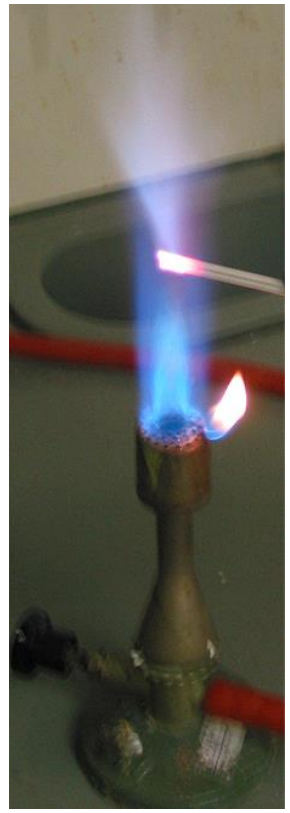

Figure 3 | Flame test: lead colors flame pale blue Herge, public domain 


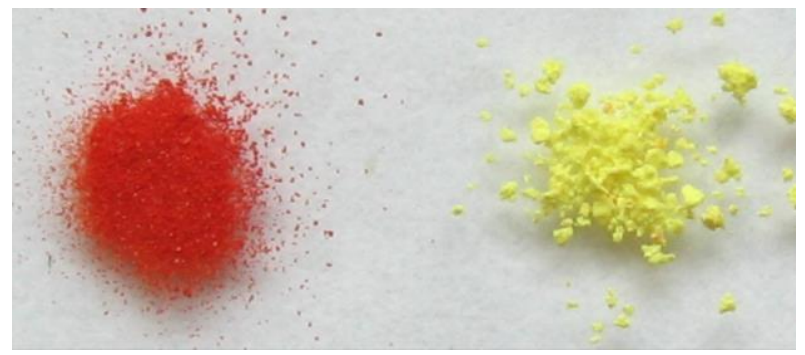

Figure 4 | Polymorphs of lead(II) oxide, litharge ( $\alpha-\mathrm{PbO}$, left) and massicot ( $\beta-\mathrm{PbO}$, right).

Hubertus Giefers, public domain

The result is a stronger contraction of the lead $6 \mathrm{~s}$ orbital than is the case for the $6 p$ orbital, making it rather inert in ionic compounds. The inert pair effect is less applicable to compounds in which lead forms covalent bonds with elements of similar electronegativity, such as carbon in organolead compounds. In these, the $6 s$ and $6 p$ orbitals remain similarly sized and $\mathrm{sp}^{3}$ hybridization is still energetically favorable. Lead, like carbon, is predominantly tetravalent in such compounds. ${ }^{[53]}$

There is a relatively large difference in the electronegativity of lead(II) at 1.87 and lead(IV) at 2.33. This difference marks the reversal in the trend of increasing stability of the +4 oxidation state going down carbon group; tin, by comparison, has values of 1.80 in the +2 oxidation state and 1.96 in the +4 state. ${ }^{[54]}$

\section{Lead(II)}

Lead(II) compounds are characteristic of the inorganic chemistry of lead. Even strong oxidizing agents like fluorine and chlorine react with lead to give only $\mathrm{PbF}_{2}$ and $\mathrm{PbCl}_{2}{ }^{\left[{ }^{[7]}\right.}$ Lead(II) ions are usually colorless in solution. ${ }^{[55]}$ No simple hydroxide is found; in aqueous solution, the lead(II) ion undergoes a series of $\mathrm{pH}$-dependent hydrolysis and condensation reactions, including $\mathrm{Pb}(\mathrm{OH})+$ and the most common hydrolysis product, $\left.[\mathrm{Pb} 4(\mathrm{OH}) 4] 4+. \mathrm{b}_{4}(\mathrm{OH})_{4}\right]^{4+}$ (in which the hydroxyl ions act as bridging ligands). ${ }^{[56][57]}$ Lead(II) ions are not reducing agents as tin(II) ions are. Techniques for identifying the presence of the $\mathrm{Pb}^{2+}$ ion in water generally rely on the precipitation of lead(II) chloride using dilute hydrochloric acid. As the chloride salt is sparingly soluble in water, in very dilute solutions the precipitation of lead(II) sulfide is achieved by bubbling hydrogen sulfide through the solution.. ${ }^{[58]}$

Lead monoxide exists in two polymorphs, litharge $\alpha$ $\mathrm{PbO}$ (red) and massicot $\beta-\mathrm{PbO}$ (yellow), the latter being stable only above around $488{ }^{\circ} \mathrm{C}$. It is the most commonly used inorganic compound of lead. ${ }^{[59]}$ There is no lead(II) hydroxide; increasing the $\mathrm{pH}$ of solutions of lead(II) salts leads to hydrolysis and condensation. ${ }^{[60]}$

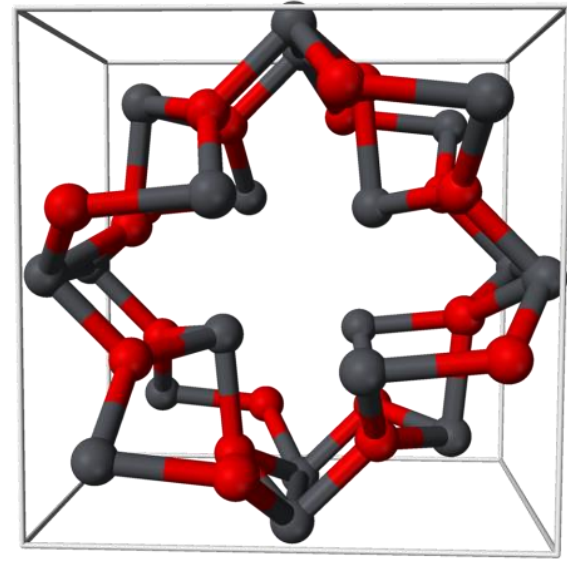

Figure 5 | Lead and oxygen in a tetragonal unit cell of lead(II,IV) oxide.

\begin{tabular}{l} 
Lead \\
\hline Oxygen
\end{tabular}

Ben Mills, public domain

Lead commonly reacts with heavier chalcogens. Lead sulfide is a semiconductor, a photoconductor, and an extremely sensitive infrared radiation detector. The other two chalcogenides, lead selenide and lead telluride, are likewise photoconducting. They are unusual in that their color becomes lighter going down the group. ${ }^{[61]}$

Lead dihalides are well-characterized; this includes the diastatide, ${ }^{[62]}$ and mixed halides, such as $\mathrm{PbFCl}$. The relative insolubility of the latter forms a useful basis for the gravimetricdetermination of fluorine. The difluoride was the first solid ionically conducting compound to be discovered (in 1834, by Michael Faraday). ${ }^{[63]}$ The other dihalides decompose on exposure to ultraviolet or visible light, especially the diiodide. ${ }^{[64]}$ Many lead(II) pseudohalides are known, such as the cyanide, cyanate, and thiocyanate. ${ }^{[61][65]}$ Lead(II) forms an extensive variety of halide coordination complexes, such as $\left[\mathrm{PbCl}_{4}\right]^{2-}$, $\left[\mathrm{PbCl}_{6}\right]^{4-}$, and the $\left[\mathrm{Pb}_{2} \mathrm{Cl}_{9}\right]_{n}{ }^{5 n-}$ chain anion. ${ }^{[64]}$

Lead(II) sulfate is insoluble in water, like the sulfates of other heavy divalent cations. Lead(II) nitrate and lead(II) acetate are very soluble, and this is exploited in the synthesis of other lead compounds. ${ }^{[66]}$

\section{Lead(IV)}

Few inorganic lead(IV) compounds are known. They are only formed in highly oxidizing solutions and do not normally exist under standard conditions. ${ }^{[67]}$ Lead(II) oxide gives a mixed oxide on further oxidation, $\mathrm{Pb}_{3} \mathrm{O}_{4}$. It is described as lead(II,IV) oxide, or structurally $2 \mathrm{PbO} \cdot \mathrm{PbO}_{2}$, and is the best-known mixed valence lead 


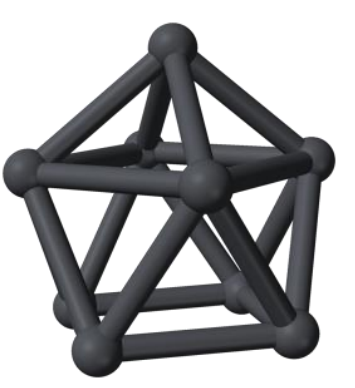

Figure 6 | The capped square antiprismatic anion $\left[\mathrm{Pb}_{9}\right]^{4-}$. [73] Ben Mills, public domain compound. Lead dioxide is a strong oxidizing agent, capable of oxidizing hydrochloric acid to chlorine gas. ${ }^{[68]}$ This is because the expected $\mathrm{PbCl}_{4}$ that would be produced is unstable and spontaneously decomposes to $\mathrm{PbCl}_{2}$ and $\mathrm{Cl}_{2}$. ${ }^{[69]}$ Analogously to lead monoxide, lead dioxide is capable of forming plumbate anions. Lead disul-

fide $^{[70]}$ and lead diselenide ${ }^{[71]}$ are only stable at high pressures. Lead tetrafluoride, a yellow crystalline powder, is stable, but less so than the difluoride. Lead tetrachloride (a yellow oil) decomposes at room temperature, lead tetrabromide is less stable still, and the existence of lead tetraiodide is questionable. ${ }^{[72]}$

\section{Other oxidation states}

Some lead compounds exist in formal oxidation states other than +4 or +2 . Lead(III) may be obtained, as an intermediate between lead(II) and lead(IV), in larger organolead complexes; this oxidation state is not stable, as both the lead(III) ion and the larger complexes containing it are radicals. ${ }^{[74][75][76]}$ The same applies for lead(I), which can be found in such radical species. ${ }^{[77]}$

Numerous mixed lead(II,IV) oxides are known. When $\mathrm{PbO}_{2}$ is heated in air, it becomes $\mathrm{Pb}_{12} \mathrm{O}_{19}$ at $293{ }^{\circ} \mathrm{C}$, $\mathrm{Pb}_{12} \mathrm{O}_{17}$ at $351{ }^{\circ} \mathrm{C}, \mathrm{Pb}_{3} \mathrm{O}_{4}$ at $374{ }^{\circ} \mathrm{C}$, and finally $\mathrm{PbO}$ at $605^{\circ} \mathrm{C}$. A further sesquioxide, $\mathrm{Pb}_{2} \mathrm{O}_{3}$, can be obtained at high pressure, along with several non-stoichiometric phases. Many of them show defective fluorite structures in which some oxygen atoms are replaced by vacancies: PbO can be considered as having such a structure, with every alternate layer of oxygen atoms absent. ${ }^{[78]}$

Negative oxidation states can occur as Zintl phases, as either free lead anions, as in $\mathrm{Ba}_{2} \mathrm{~Pb}$, with lead formally being lead(-IV), ${ }^{[79]}$ or in oxygen-sensitive ring-shaped or polyhedral cluster ions such as the trigonal bipyramidal $\mathrm{Pb}_{5}{ }^{2-}$ ion, where two lead atoms are lead(-I) and three are lead(0). ${ }^{[80]}$ In such anions, each atom is at a polyhedral vertex and contributes two electrons to each covalent bond along an edge from their $\mathrm{sp}^{3}$ hybrid orbitals, the other two being an external lone pair. ${ }^{[56]}$ They may be made in liquid ammonia via the reduction of lead by sodium. ${ }^{[81]}$

\section{Organolead}

Lead can form multiply-bonded chains, a property it shares with its lighter homologs in the carbon group. The capacity for catenation decreases going down the group due to decreasing bond energy. The $\mathrm{Pb}-\mathrm{Pb}$ bond energy is over three and a half times lower than that of the $\mathrm{C}-\mathrm{C}$ bond. ${ }^{[50]}$ With itself lead can build metal-metal bonds of an order up to three. ${ }^{[82]}$ With carbon, lead forms organolead compounds similar to, but generally less stable than, typical organic compounds ${ }^{[83]}$ (due to the $\mathrm{Pb}-\mathrm{C}$ bond being rather weak). ${ }^{[56]}$ This makes the organometallic chemistry of lead far less wide-ranging than that of tin. ${ }^{\left[{ }^{84]}\right.}$ Lead predominantly forms organolead(IV) compounds, even when starting with inorganic lead(II) reactants; very few organolead(II) compounds are known. The most well-characterized exceptions are $\mathrm{Pb}\left[\mathrm{CH}\left(\mathrm{SiMe}_{3}\right)_{2}\right]_{2}$ and $\mathrm{Pb}\left(\eta^{5}-\mathrm{C}_{5} \mathrm{H}_{5}\right)_{2}$. ${ }^{\left[{ }^{84}\right]}$

The lead analog of the simplest organic compound, methane, is plumbane. Plumbane may be obtained in a reaction between metallic lead and atomic hydrogen. ${ }^{[85]}$ It is thermodynamically unstable and its chemistry has not been determined. ${ }^{[86]}$ Two simple derivatives, tetramethyllead and tetraethyllead, are the best-known organolead compounds. These compounds are relatively stable: tetraethyllead only starts to decompose if heated $^{[87]}$ or if exposed to sunlight or ultraviolet light. ${ }^{[88]}$ (Tetraphenyllead is even more thermally stable, decomposing at $270^{\circ} \mathrm{C} .{ }^{[84]}$ ) With sodium metal, lead readily forms an equimolar alloy that reacts with alkyl hal-

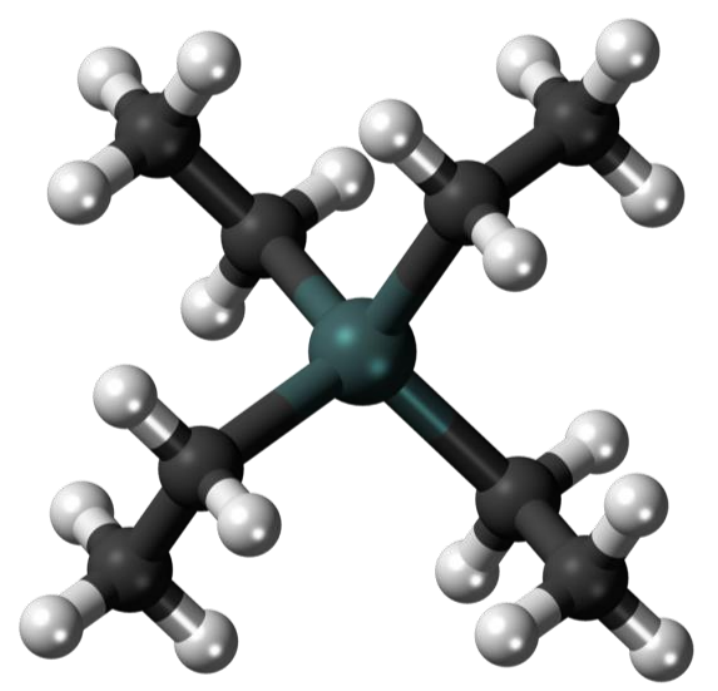

Figure 7 | Structure of a tetraethyllead molecule

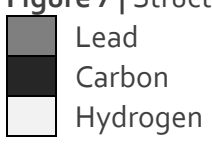

Jynto, public domain 
ides to form organometalliccompounds such as tetraethyllead. ${ }^{[89]}$ The oxidizing nature of many organolead compounds is usefully exploited: lead tetraacetate is an important laboratory reagent for oxidation in organic synthesis, ${ }^{[90]}$ and tetraethyllead was once produced in larger quantities than any other organometallic compound. ${ }^{\left[{ }^{[4]}\right.}$ Other organolead compounds are less chemically stable ${ }^{[83]}$ For many organic compounds, a lead analog does not exist. ${ }^{[85]}$

\section{Origin and occurrence}

\section{In space}

Lead's per-particle abundance in the Solar System is $0.121 \mathrm{ppb}$ (parts per billion). ${ }^{[91][\mathrm{k}]}$ This figure is two and a half times higher than that of platinum, eight times more than mercury, and seventeen times more than gold. ${ }^{[91]}$ The amount of lead in the universe is slowly increasing ${ }^{[92]}$ as most heavier atoms (all of which are unstable) gradually decay to lead. ${ }^{[93]}$ The abundance of lead in the Solar System since its formation 4.5 billion years ago has increased by about $0.75 \% \cdot{ }^{[94]}$ The solar system abundances table shows that lead, despite its relatively high atomic number, is more prevalent than most other elements with atomic numbers greater than 40. ${ }^{[91]}$

Primordial lead-which comprises the isotopes lead204, lead-206, lead-207, and lead-208-was mostly created as a result of repetitive neutron capture processes

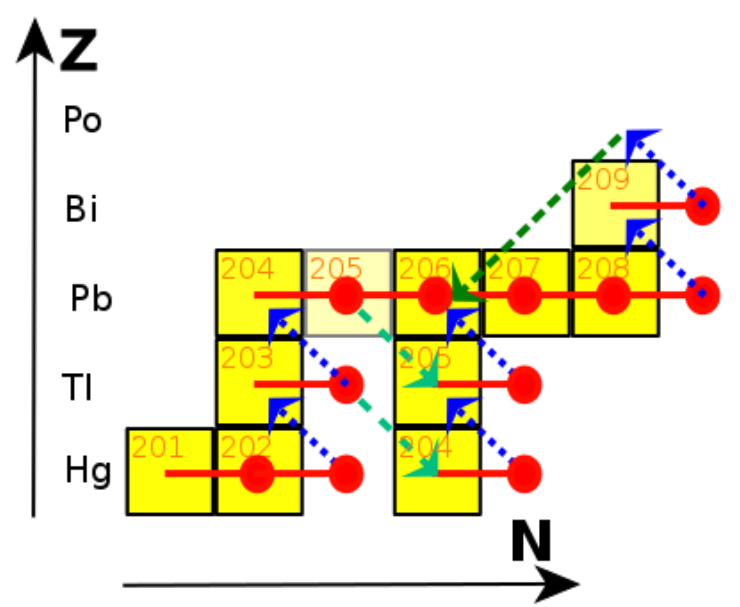

Figure 8 | Chart of the final part of the s-process, from mercury to polonium. Red lines and circles represent neutron captures; blue arrows represent beta decays; the green arrow represents an alpha decay; cyan arrows represent electron captures.

occurring in stars. The two main modes of capture are the $s$ - and r-processes. ${ }^{[95]}$

In the s-process (s is for "slow"), captures are separated by years or decades, allowing less stable nuclei to undergo beta decay. ${ }^{[96]} \mathrm{A}$ stable thallium-203 nucleus can capture a neutron and become thallium-204; this undergoes beta decay to give stable lead-204; on capturing another neutron, it becomes lead-205, which has a half-life of around 15 million years. Further captures result in lead-206, lead-207, and lead-208. On capturing

\begin{tabular}{ccr}
\hline $\begin{array}{c}\text { Atomic } \\
\text { number }\end{array}$ & Element & $\begin{array}{r}\text { Relative } \\
\text { amount }\end{array}$ \\
\hline 42 & Molybdenum & 0.798 \\
46 & Palladium & 0.440 \\
50 & Tin & 1.146 \\
78 & Platinum & 0.417 \\
80 & Mercury & 0.127 \\
82 & Lead & 1 \\
90 & Thorium & 0.011 \\
92 & Uranium & 0.003 \\
\hline
\end{tabular}

Table 2 | Solar System abundances ${ }^{[91]}$

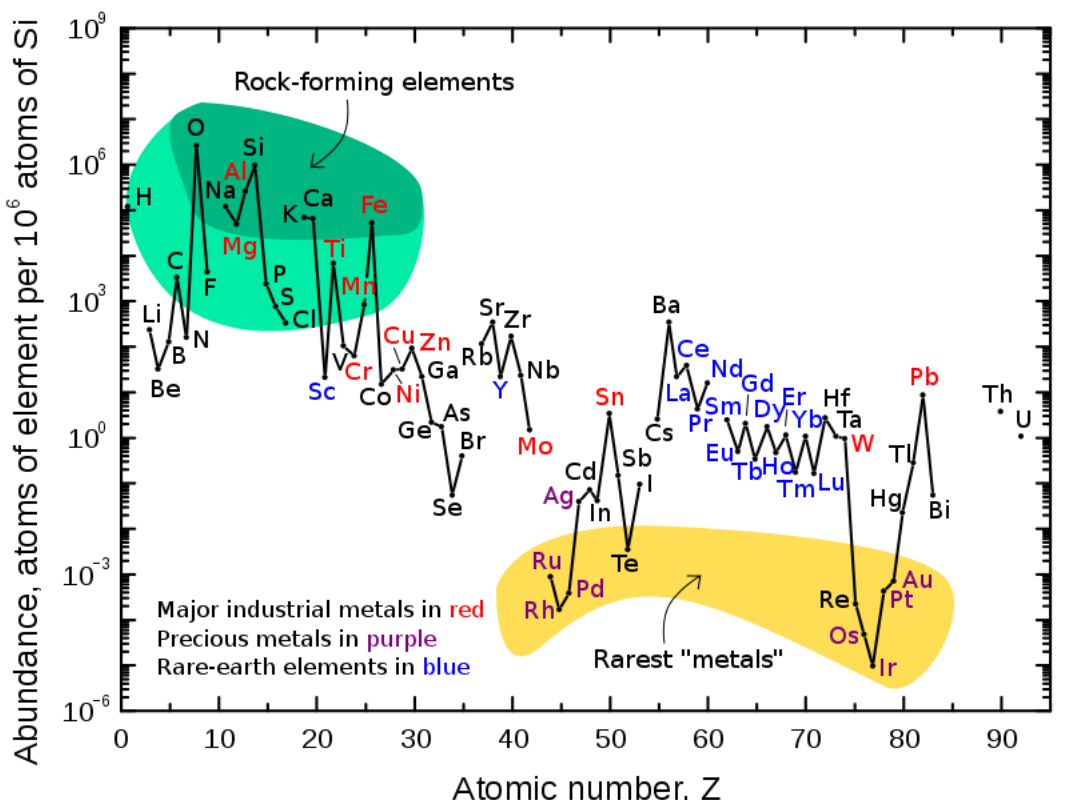

Figure 9 | Lead is a fairly common element in the Earth's crust for its high atomic number (82). Most elements of atomic number greater than 40 are less abundant. Gordon Haxel, Sara Boore, Susan Mayfield, public domain 
another neutron, lead-208 becomes lead-209, which quickly decays into bismuth-209. On capturing another neutron, bismuth-209 becomes bismuth-210, and this beta decays to polonium-210, which alpha decays to lead-206. The cycle hence ends at lead-206, lead-207, lead-208, and bismuth-209. ${ }^{[97]}$

In the $r$-process ( $r$ is for "rapid"), captures happen faster than nuclei can decay. ${ }^{[98]}$ This occurs in environments with a high neutron density, such as a supernova or the merger of two neutron stars. The neutron flux involved may be on the order of $10^{22}$ neutrons per square centimeter per second. ${ }^{[99]}$ The r-process does not form as much lead as the s-process. ${ }^{[100]}$ It tends to stop once neutron-rich nuclei reach 126 neutrons. ${ }^{[101]}$ At this point, the neutrons are arranged in complete shells in the atomic nucleus, and it becomes harder to energetically accommodate more of them. ${ }^{[102]}$ When the neutron flux subsides, these nuclei beta decay into stable isotopes of osmium, iridium, and platinum. ${ }^{[103]}$

\section{On Earth}

Lead is classified as a chalcophile under the Goldschmidt classification, meaning it is generally found combined with sulfur. ${ }^{[104]}$ It rarely occurs in its native, metallic form. ${ }^{[105]}$ Many lead minerals are relatively light and, over the course of the Earth's history, have remained in the crust instead of sinking deeper into the Earth's interior. This accounts for lead's relatively high crustal abundance of 14 ppm; it is the 38th most abundantelement in the crust. ${ }^{[06][1]}$

The main lead-bearing mineral is galena $(\mathrm{PbS})$, which is mostly found with zinc ores. ${ }^{[108]}$ Most other lead minerals are related to galena in some way; boulangerite, $\mathrm{Pb}_{5} \mathrm{Sb}_{4} \mathrm{~S}_{11}$, is a mixed sulfide derived from galena; anglesite, $\mathrm{PbSO}_{4}$, is a product of galena oxidation; and cerussite or white lead ore, $\mathrm{PbCO}_{3}$, is a decomposition product of galena. Arsenic, tin, antimony, silver, gold, copper, and bismuth are common impurities in lead minerals. ${ }^{[108]}$

World lead resources exceed 2 billion tons. Significant deposits are located in Australia, China, Ireland, Mexico, Peru, Portugal, Russia, and the United States. Global reserves-resources that are economically feasible to extract-totaled 88 million tons in 2016, of which Australia had 35 million, China 17 million, and Russia 6.4 million. ${ }^{[109]}$

Typical background concentrations of lead do not exceed $0.1 \mu \mathrm{g} / \mathrm{m}^{3}$ in the atmosphere; $100 \mathrm{mg} / \mathrm{kg}$ in soil; and $5 \mu \mathrm{g} / \mathrm{L}$ in freshwater and seawater. ${ }^{[110]}$

$\mathbf{7}$ of $\mathbf{2 3}$ | WikiJournal of Science

\section{Etymology}

The modern English word "lead" is of Germanic origin; it comes from the Middle English leed and Old English lead (with the macron above the "e" signifying that the vowel sound of that letter is long). ${ }^{[111]}$ The Old English word is derived from the hypothetical reconstructed Proto-Germanic *lauda- ("lead"). ${ }^{[112]}$ According to linguistic theory, this word bore descendants in multiple Germanic languages of exactly the same meaning. ${ }^{[112]}$

The origin of the Proto-Germanic *lauda- is not agreed in the linguistic community. One hypothesis suggests it is derived from Proto-Indo-European *lAudh- ("lead"; capitalization of the vowel is equivalent to the macron). ${ }^{[13]}$ Another hypothesis suggests it is borrowed from Proto-Celtic * lated to the Latin plumbum, which gave the element its chemical symbol $P b$. The word * $\varphi$ loud-io- is thought to be the origin of Proto-Germanic *bliwa- (which also means "lead"), from which stemmed the German Blei. ${ }^{[114]}$

The name of the chemical element is not related to the verb of the same spelling, which is derived from ProtoGermanic *laidijan- ("to lead"). ${ }^{[115]}$

\section{History}

\section{Prehistory and early history}

Metallic lead beads dating back to 7000-6500 BCE have been found in Asia Minor and may represent the first example of metal smelting. ${ }^{[117]}$ At that time lead had few (if any) applications due to its softness and dull appearance. ${ }^{[117]}$ The major reason for the spread of lead production was its association with silver, which may be obtained by burning galena (a common lead mineral). ${ }^{[118]}$ The Ancient Egyptians were the first to use lead minerals in cosmetics, an application that spread to Ancient Greece and beyond; ${ }^{[119]}$ the Egyptians may have used lead for sinkers in fishing nets, glazes, glasses, enamels, and for ornaments. ${ }^{[118]}$ Various civilizations of the Fertile Crescent used lead as a writing material, as currency, and for construction. ${ }^{[118]}$ Lead was used in the Ancient Chinese royal court as a stimulant, ${ }^{[118]}$ as currency, ${ }^{[120]}$ and as a contraceptive; ${ }^{[121]}$ the Indus Valley civilization and the Mesoamericans ${ }^{[118]}$ used it for making amulets; and the eastern and southern African peoples used lead in wire drawing. ${ }^{[122]}$

\section{Classical era}

Because silver was extensively used as a decorative material and an exchange medium, lead deposits came to 


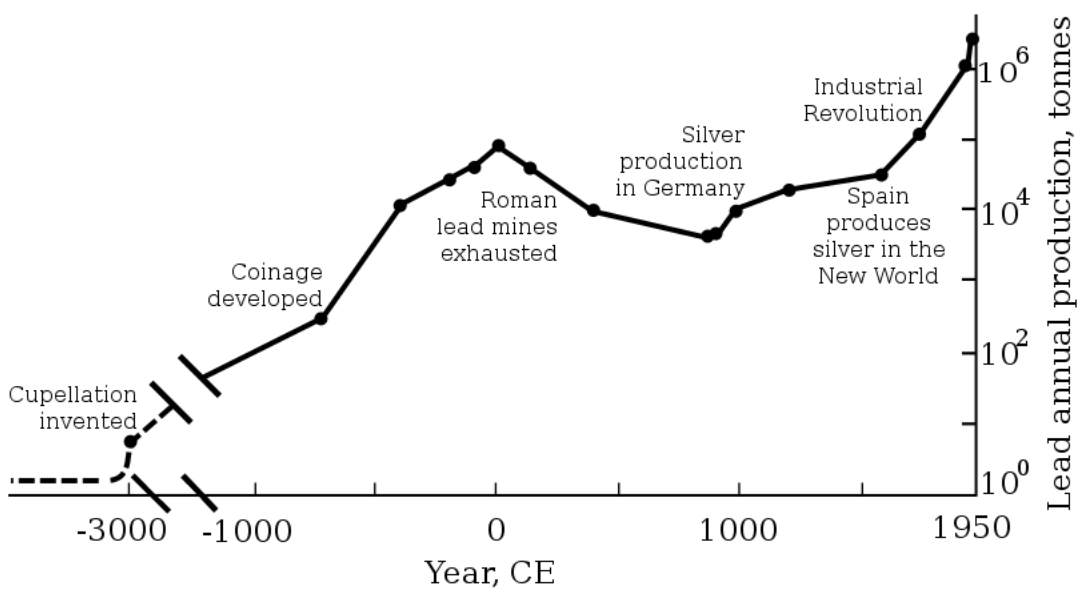

Figure 10 | World lead production peaking in the Roman period and the Industrial Revolution. [116]

Fox 52, CC-BY-SA 4.0

be worked in Asia Minor since 3000 BCE; later, lead deposits were developed throughout Mediterranea. ${ }^{[124][125]}$

Rome's territorial expansion in Europe and across the Mediterranean, and its development of mining, led to it becoming the greatest producer of lead during the classical era, with an estimated annual output peaking at 80,000 tonnes. Like their predecessors, the Romans obtained lead mostly as a by-product of silver smelting. ${ }^{[116][126]}$

"This metal was by far the most used material in classical antiqvity, and it is appropriate to refer to the (Roman) Lead Age. Lead was to the Romans what plastic is to us."

Heinz Eschnaver and Markus Stoeppler "Wine-An enological specimen bank", 1992 $2^{[127]}$

Lead was used for making water pipes; the Latin word for the metal, plumbum, is the origin of the English word "plumbing". Its ease of working and resistance to corrosion $^{[128]}$ ensured its widespread use in other applications including pharmaceuticals, roofing, currency, and warfare. ${ }^{[129][130][131]}$ Writers of the time recommended lead (or lead-coated) vessels for the preparation of sweeteners and preservatives added to wine and food. The lead

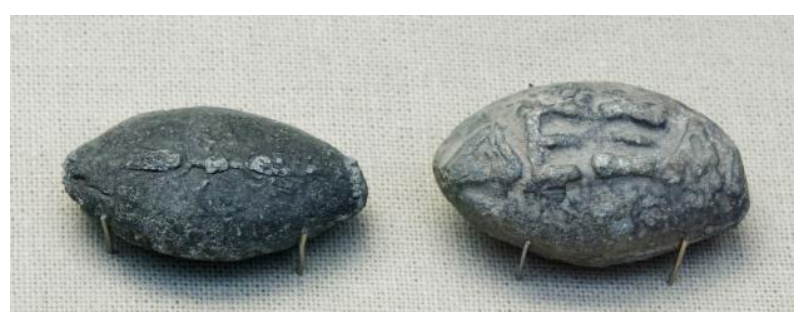

Figure 11 | Ancient Greek lead sling bullets with a winged thunderbolt molded on one side and the inscription " $\triangle \mathrm{E}=\mathrm{Al}$ " ("take that" or "catch") on the other side ${ }^{[123]}$

Marie-Lan Nguyen, public domain conferred an agreeable taste due to the formation of "sugar of lead" (lead(II) acetate), whereas copper or bronze vessels could impart a bitter flavor through verdigris formation. ${ }^{[132]}$

The Roman author Vitruvius reported the health dangers of lead ${ }^{[133]}$ and modern writers have suggested that lead poisoning played a major role in the decline of the Roman Empire. ${ }^{[134][135][\mathrm{m}]}$ Other researchers have criticized such claims, pointing out, for instance, that not all abdominal pain is caused by lead poisoning. ${ }^{[137][138]}$ According to archaeological research, Roman lead pipes increased lead levels in tap water but such an effect was "unlikely to have been truly harmful". [139][140] When lead poisoning did occur, victims were called "saturnine", dark and cynical, after the ghoulish father of the gods, Saturn. By association, lead was considered the father of all metals. ${ }^{[141]}$ Its status in Roman society was low as it was readily available ${ }^{[142]}$ and cheap. ${ }^{[143]}$

\section{Confusion with tin and antimony}

During the classical era (and even up to the 17th century), tin was often not distinguished from lead: Romans called lead plumbum nigrum ("black lead"), and tin plumbum candidum ("bright lead"). The association of lead and tin can be seen in other languages: the word olovo in Czech translates to "lead", but in Russian the cognate олово (olovo) means "tin". ${ }^{[144]}$ To add to the confusion, lead bore a close relation to antimony: both elements commonly occur as sulfides (galena and stib-

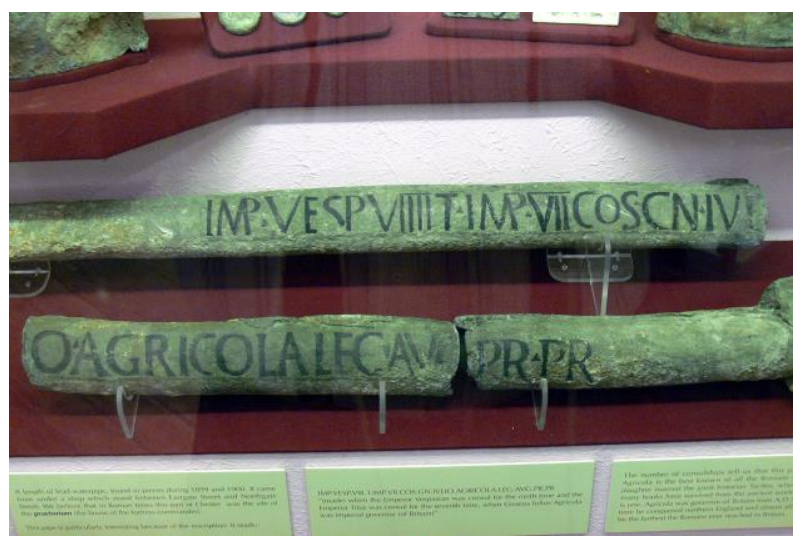

Figure 12 | Roman lead pipes ${ }^{[\mathrm{n}]}$

Wolfgang Sauber, CC-BY-SA 3.0 
nite), often together. Pliny incorrectly wrote that stibnite would give lead on heating, instead of antimony. ${ }^{[145]}$ In countries such as Turkey and India, the originally Persian name surma came to refer to either antimony sulfide or lead sulfide, ${ }^{[146]}$ and in some languages, such as Russian, gave its name to antimony (сурьма). ${ }^{[147]}$

\section{Middle Ages and the Renaissance}

Lead mining in Western Europe declined after the fall of the Western Roman Empire, with Arabian Iberia being the only region having a significant output. ${ }^{[148][149]}$ The largest production of lead occurred in South and East Asia, especially China and India, where lead mining grew strongly. ${ }^{[149]}$

In Europe, lead production only began to revive in the 11th and 12th centuries, when it was again used for roofing and piping. Starting in the 13th century, lead was used to create stained glass. ${ }^{[151]}$ In the European and Arabiantraditions of alchemy, lead was considered an impure base metal which, by the separation, purification and balancing of its constituent essences, could be transformed to pure and incorruptible gold. ${ }^{[152]}$ During the period, lead was used increasingly for adulterating wine. The use of such wine was forbidden for use in

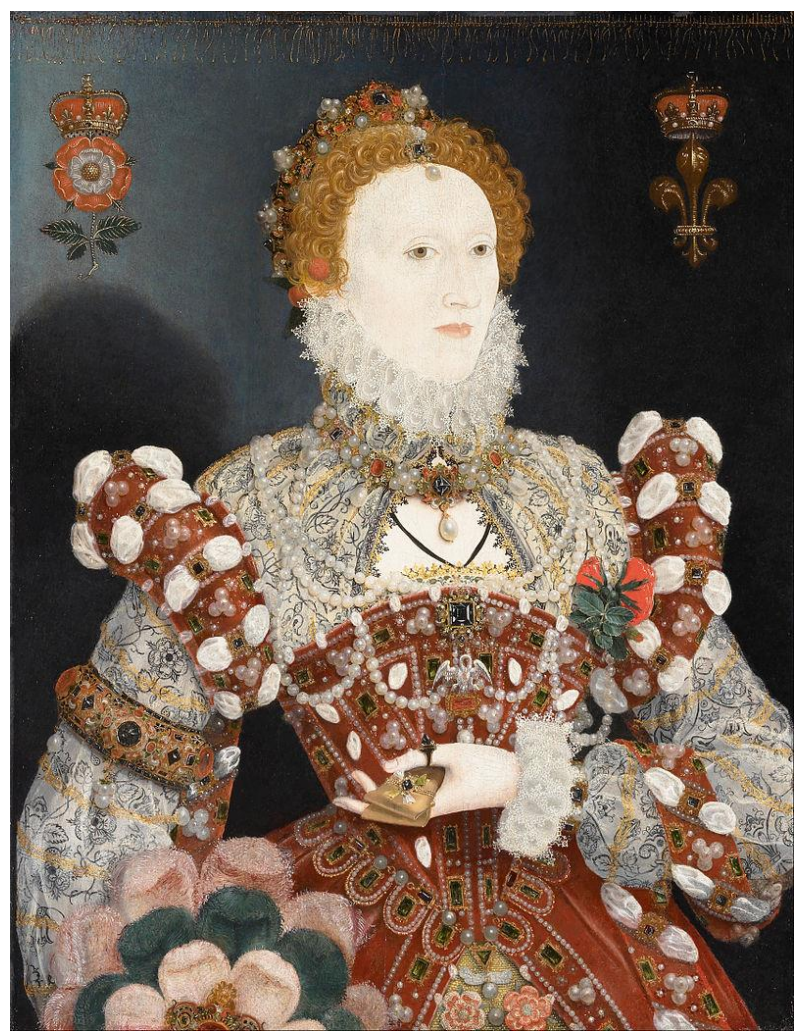

Figure 13 | Elizabeth I of England was commonly depicted with a whitened face. Lead in face whiteners is thought to have contributed to her death. ${ }^{[150]}$

Nicholas Hilliard, public domain
Christian rites by a papal bull in 1498 , but it continued to be imbibed and resulted in mass poisonings up to the late 18 th century. ${ }^{[148][153]}$ Lead was a key material in parts of the printing press, which was invented around 1440; lead dust was commonly inhaled by print workers, causing lead poisoning. ${ }^{[154]}$ Firearms were invented at around the same time, and lead, despite being more expensive than iron, became the chief material for making bullets. It was less damaging to iron gun barrels, had a higher density (which allowed for better retention of velocity), and its lower melting point made the production of bullets easier as they could be made using a wood fire. ${ }^{[155]}$ Lead, in the form of Venetian ceruse, was extensively used in cosmetics by Western European aristocracy as whitened faces were regarded as a sign of modesty. ${ }^{[156][157]}$ This practice later expanded to white wigs and eyeliners, and only faded out with the French Revolution in the late 18th century. A similar fashion appeared in Japan in the 18th century with the emergence of the geishas, a practice that continued long into the 20th century. The white faces of women "came to represent their feminine virtue as Japanese women", ${ }^{[158]}$ with lead commonly used in the whitener. ${ }^{[159]}$

\section{Outside Europe and Asia}

In the New World, lead was produced soon after the arrival of European settlers. The earliest recorded lead production dates to 1621 in the English Colony of Virginia, fourteen years after its foundation. ${ }^{[160]}$ In Australia, the first mine opened by colonists on the continent was a lead mine, in 1841. ${ }^{[161]}$ In Africa, lead mining and smelting were known in the Benue Trough ${ }^{[162]}$ and the lower Congo Basin, where lead was used for trade with Europeans and as a currency by the 17th century, ${ }^{[163]}$ well before the scramble for Africa.

\section{Industrial Revolution}

In the second half of the 18th century, Britain, and later continental Europe and the United States, experienced

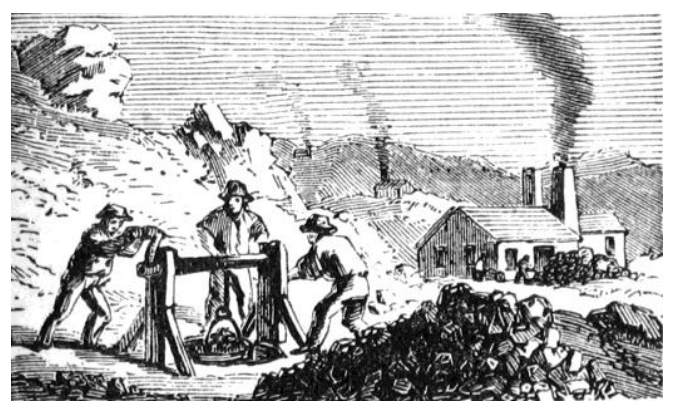

Figure 14 | Lead mining in the upper Mississippi River region in the United States in 1865.

John Barber and Henry Howe, public domain 
the Industrial Revolution. This was the first time during which production rates exceeded those of Rome. ${ }^{[116]}$ Britain was the leading producer, losing this status by the mid-19th century with the depletion of its mines and the development of lead mining in Germany, Spain, and the United States. ${ }^{[164]}$ By 1900, the United States was the leader in global lead production, and other nonEuropean nations-Canada, Mexico, and Australiahad begun significant production; production outside Europe exceeded that within. ${ }^{[165]} \mathrm{A}$ great share of the demand for lead came from plumbing and paintinglead paints were in regular use. ${ }^{[166]}$ At this time, more (working class) people were exposed to the metal and lead poisoning cases escalated. This led to research into the effects of lead intake. Lead was proven to be more dangerous in its fume form than as a solid metal. Lead poisoning and gout were linked. The effects of chronic ingestion of lead, including mental disorders, were also studied in the 19th century. The first laws aimed at decreasing lead poisoning in factories were enacted during the 1870s and 1880s in the United Kingdom. ${ }^{[166]}$

\section{Modern era}

Further evidence of the threat that lead posed to humans was discovered in the late 19th and early 20th centuries. Mechanisms of harm were better understood, lead blindness was documented, and the element was phased out of public use in the United States and Europe. The United Kingdom introduced mandatory factory inspections in 1878 and appointed the first Medical Inspector of Factories in 1898; as a result, a 25fold decrease in lead poisoning incidents from 1900 to 1944 was reported. ${ }^{[167]}$ The last major human exposure to lead was the addition of tetraethyllead to gasoline as an antiknock agent, a practice that originated in the United States in 1921. It was phased out in the United States and the European Union by 2000. ${ }^{[166]}$ Most European countries banned lead paint-commonly used because of its opacity and water resistance ${ }^{[168]}$-for interiors by $1930 .{ }^{[169]}$

In the 1970s, the United States and Western European countries introduced legislation to reduce lead air pollution. ${ }^{[170][171]}$ The impact was significant: the share of people in the United States with elevated blood lead levels fell from $77.8 \%$ in $1976-1980$ to $2.2 \%$ in $1991-$ $1994 .{ }^{[172]}$ The main product made of lead by the end of the 20th century was the lead-acid battery, ${ }^{[173]}$ which posed no direct threat to humans. From 1960 to 1990, lead output in the Western Bloc grew by a third. ${ }^{[174]}$ The share of the world's lead production by the Eastern Bloc increased from $10 \%$ to $30 \%$, from 1950 to 1990, with the Soviet Union being the world's largest producer during the mid-1970s and the 1980s, and China starting major lead production in the late 20th century. ${ }^{[175]}$ Unlike the European communist countries, China was largely unindustrialized by the mid-20th century; in 2004, China surpassed Australia as the largest producer of lead. ${ }^{[176]}$ As was the case during European industrialization, lead has had a negative effect on health in China. ${ }^{[177]}$

\section{Production}

Production of lead is increasing worldwide due to its use in lead-acid batteries. ${ }^{[178]}$ There are two major categories of production: primary from mined ores, and secondary from scrap. In 2014, 4.58 million metric tons came from primary production and 5.64 million from secondary production. The top three producers of mined lead concentrate in that year were China, Australia, and the United States. The top three producers of refined lead were China, the United States, and South Korea. ${ }^{[179]}$ According to the International Resource Panel's Metal Stocks in Society report of 2010, the total amount of lead in use, stockpiled, discarded, or dissipated into the environment, on a global basis, is $8 \mathrm{~kg}$ per capita. Much of this is in more developed countries (20-150 kg per capita) rather than less developed ones (1-4 kg per capita). ${ }^{[180]}$

The primary and secondary lead production processes are similar. Some primary production plants now supplement their operations with scrap lead, and this trend is likely to increase in the future. Given adequate techniques, lead obtained via secondary processes is indistinguishable from lead obtained via primary processes. Scrap lead from the building trade is usually fairly clean and is re-melted without the need for smelting, though refining is sometimes needed. Secondary lead production is therefore cheaper, in terms of energy requirements, than is primary production, often by $50 \%$ or more. ${ }^{[181]}$

\section{Primary}

Most lead ores contain a low percentage of lead (rich ores have a typical content of 3-8\%) which must be concentrated for extraction. ${ }^{[182]}$ During initial processing, ores typically undergo crushing, dense-medium separation, grinding, froth flotation, and drying. The resulting concentrate, which has a lead content of $30-80 \%$ by mass (regularly $50-60 \%)_{1}^{[182]}$ is then turned into (impure) lead metal.

There are two main ways of doing this: a two-stage process involving roasting followed by blast furnace extraction, carried out in separate vessels; or a direct process in which the extraction of the concentrate occurs in a 
single vessel. The latter has become the most common route, though the former is still significant. ${ }^{[183]}$

\section{Two-stage process}

First, the sulfide concentrate is roasted in air to oxidize the lead sulfide: ${ }^{[184]}$

$$
2 \mathrm{PbS}(\mathrm{s})+3 \mathrm{O}_{2}(\mathrm{~g}) \rightarrow 2 \mathrm{PbO}(\mathrm{s})+2 \mathrm{SO}_{2}(\mathrm{~g})
$$

As the original concentrate was not pure lead sulfide, roasting yields not only the desired lead(II) oxide, but a mixture of oxides, sulfates and silicates of lead and other metals contained in the ore. ${ }^{[185]}$ This impure lead oxide is reduced in a coke-fired blast furnace to the (again, impure) metal: ${ }^{[186]}$

$$
2 \mathrm{PbO}(\mathrm{s})+\mathrm{C}(\mathrm{s}) \rightarrow 2 \mathrm{~Pb}(\mathrm{~s})+\mathrm{CO}_{2}(\mathrm{~g})
$$

Impurities are mostly arsenic, antimony, bismuth, zinc, copper, silver, and gold. The melt is treated in a reverberatory furnace with air, steam, and sulfur, which oxidizes the impurities except for silver, gold, and bismuth. Oxidized contaminants float to the top of the melt and are skimmed off. ${ }^{[187][188]}$ Metallic silver and gold are removed and recovered economically by means of the Parkes process, in which zinc is added to lead. The zinc, which is immiscible in lead, dissolves in silver and gold. The zinc solution can be separated from the lead, and the silver and gold retrieved. ${ }^{[189][188]}$ De-silvered lead is freed of bismuth by the Betterton-Kroll process, treating it with metallic calcium and magnesium. The resulting bismuth dross can be skimmed off. ${ }^{[188]}$

Annual production ( $\mathrm{Mt} \mathrm{Pb}$ )

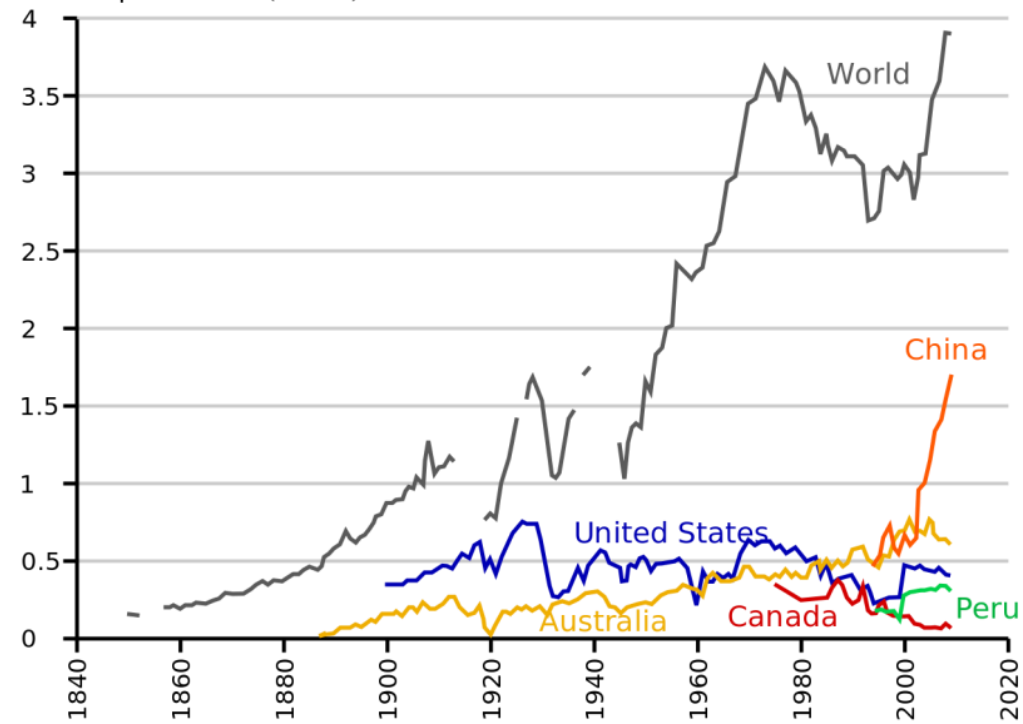

Figure 15 | Primary production of lead since 1840 Borvan53, CC-BY-SA 4.0
Very pure lead can be obtained by processing smelted lead electrolytically using the Betts process. Anodes of impure lead and cathodes of pure lead are placed in an electrolyte of lead fluorosilicate $\left(\mathrm{PbSiF}_{6}\right)$. Once electrical potential is applied, impure lead at the anode dissolves and plates onto the cathode, leaving the majority of the impurities in solution. ${ }^{[188][190]}$ This is a high-cost process and thus mostly reserved for refining bullion containing high percentages of impurities. ${ }^{[191]}$

\section{Direct process}

In this process, lead bullion and slag is obtained directly from lead concentrates. The lead sulfide concentrate is melted in a furnace and oxidized, forming lead monoxide. Carbon (as coke or coal gas ${ }^{[0]}$ ) is added to the molten charge along with fluxing agents. The lead monoxide is thereby reduced to metallic lead, in the midst of a slag rich in lead monoxide. ${ }^{[183]}$

As much as $80 \%$ of the lead in very high-content initial concentrates can be obtained as bullion; the remaining $20 \%$ forms a slag rich in lead monoxide. For a low-grade feed, all of the lead can be oxidized to a high-lead slag. ${ }^{[183]}$ Metallic lead is further obtained from the highlead (25-40\%) slags via submerged fuel combustion or injection, reduction assisted by an electric furnace, or a combination of both. ${ }^{[183]}$

\begin{tabular}{lr} 
Country & $\begin{array}{c}\text { Output } \\
\text { (thousand } \\
\text { tons) }\end{array}$ \\
\hline Australia & 2,400 \\
United States & 500 \\
Peru & 335 \\
Mexico & 310 \\
Russia & 250 \\
India & 225 \\
Bolivia & 135 \\
Sweden & 80 \\
Turkey & 76 \\
\hline Iran & 75 \\
Kazakhstan & 41 \\
Poland & 41 \\
South Africa & 40 \\
North Korea & 40 \\
\hline Ireland & 35 \\
\hline Other countries & 33 \\
\hline
\end{tabular}

Table 3 | World's largest mining countries of lead, 2016[109] 


\section{Alternatives}

Research on a cleaner, less energy-intensive lead extraction process continues; a major drawback is that either too much lead is lost as waste, or the alternatives result in a high sulfur content in the resulting lead metal. Hydrometallurgical extraction, in which anodes of impure lead are immersed into an electrolyte and pure lead is deposited onto a cathode, is a technique that may have potential. ${ }^{[192]}$

\section{Secondary}

Smelting, which is an essential part of the primary production, is often skipped during secondary production. It is only performed when metallic lead had undergone significant oxidation. ${ }^{[181]}$ The process is similar to that of primary production in either a blast furnace or a rotary furnace; blast furnaces produce hard lead ( $10 \%$ antimony) while reverberatory and rotary kiln furnaces produced semisoft lead (3-4\% antimony). ${ }^{[193]}$ The Isasmelt process is a more recent method that may act as an extension to primary production; battery paste from spent lead-acid batteries has sulfur removed by treating it with alkali, and is then treated in a coal-fueled furnace in the presence of oxygen, which yields impure lead, with antimony the most common impurity. ${ }^{[194]}$ Refining of secondary lead is similar to that of primary lead. Some refining processes may be skipped depending on the material recycled and its potential contamination. ${ }^{[195]}$

Of the sources of lead for recycling, lead-acid batteries are the most important; lead pipe, sheet, and cable sheathing are also significant. ${ }^{[181]}$

\section{Applications}

Contrary to popular belief, pencil leads in wooden pencils have never been made from lead. When the pencil originated as a wrapped graphite writing tool, the particular type of graphite used was named plumbago (literally, act for lead or lead mockup). ${ }^{[197]}$

\section{Elemental form}

Lead metal has several useful mechanical properties, including high density, low melting point, ductility, and relative inertness. Many metals are superior to lead in some of these aspects but are generally less common and more difficult to extract from parent ores. Lead's toxicity has led to its phasing out for some uses. ${ }^{[198]}$

Lead has been used for bullets since their invention in the Middle Ages. It is inexpensive; its low melting point means small arms ammunition and shotgun pellets can be cast with minimal technical equipment; and it is denser than other common metals, which allows for better retention of velocity. Concerns have been raised that lead bullets used for hunting can damage the environment. ${ }^{[p]}$

Lead's high density and resistance to corrosion have been exploited in a number of related applications. It is used as ballast in sailboat keels; ${ }^{[200]}$ its density allows it to take up a small volume and minimize water resistance, thus counterbalancing the heeling effect of wind on the sails. It is used in scuba diving weight belts to counteract the diver's buoyancy. ${ }^{[201]} \ln 1993$, the base of the Leaning Tower of Pisa was stabilized with 600 tonnes of lead. ${ }^{[202]}$ Because of its corrosion resistance, lead is used as a protective sheath for underwater cables. ${ }^{[203]}$

Lead has many uses in the construction industry; lead sheets are used as architectural metals in roofing material, cladding, flashing, gutters and gutter joints, and on roof parapets. ${ }^{[204][205]}$ Detailed lead moldings are used as decorative motifs to fix lead sheet. Lead is still used in statues and sculptures, ${ }^{[9]}$ including for armatures. ${ }^{[207]}$ In the past it was often used to balance the wheels of cars; for environmental reasons this use is being phased out in favor of other materials. ${ }^{[109]}$

Lead is added to copper alloys such as brass and bronze, to improve machinability and for its lubricating qualities. Being practically insoluble in copper, lead forms solid globules in imperfections throughout the alloy, such as grain boundaries. In low concentrations, as well as acting as a lubricant, the globules hinder the formation of swarf as the alloy is worked, thereby improving machinability. Copper alloys with larger concentrations of lead are used in bearings. The lead provides lubrication, and the copper provides the load-bearing support. ${ }^{[208]}$

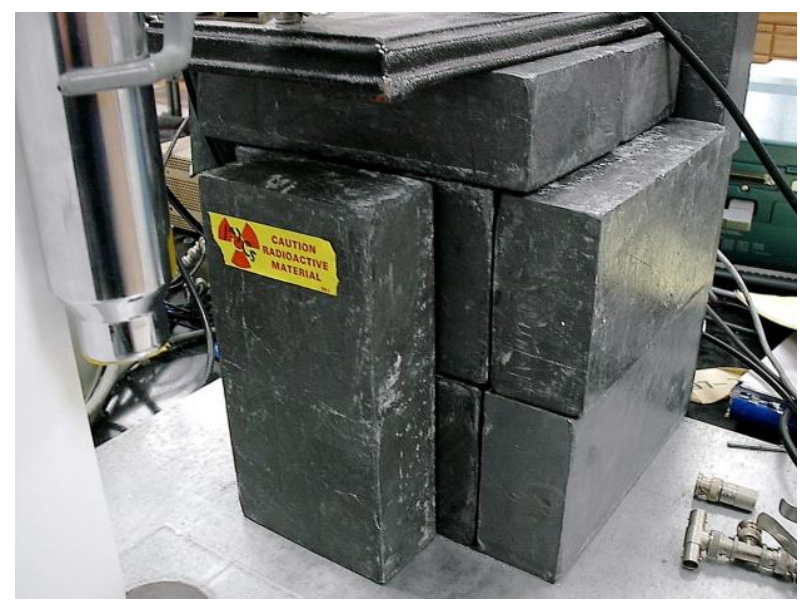

Figure 16| Bricks of lead (alloyed with 4\% antimony) are used as radiation shielding. ${ }^{[196]}$

Loren Chang, public domain 


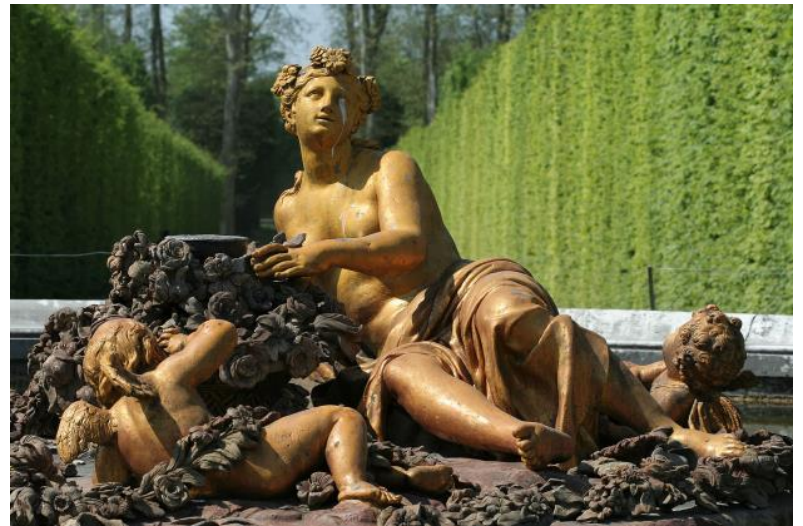

Figure 17 | A 17th-century gold-coated lead sculpture Coyau, CC-BY-SA 3.0

Lead's high density, atomic number, and formability form the basis for use of lead as a barrier that absorbs sound, vibration, and radiation. ${ }^{[209]}$ Lead has no natural resonance frequencies; ${ }^{[209]}$ as a result, sheet-lead is used as a sound deadening layer in the walls, floors, and ceilings of sound studios. ${ }^{[210]}$ Organ pipes are often made from a lead alloy, mixed with various amounts of tin to control the tone of each pipe. ${ }^{[211][212]}$ Lead is an established shielding material from radiation in nuclear science and in X-ray rooms ${ }^{[213]}$ due to its denseness and high attenuation coefficient. ${ }^{[214]}$ Molten lead has been used as a coolant for lead-cooled fast reactors. ${ }^{[215]}$

The largest use of lead in the early 21st century is in lead-acid batteries. The reactions in the battery between lead, lead dioxide, and sulfuric acid provide a reliable source of voltage. ${ }^{[r]}$ The lead in batteries undergoes no direct contact with humans, so there are fewer toxicity concerns. Supercapacitors incorporating leadacid batteries have been installed in kilowatt and megawatt scale applications in Australia, Japan, and the United States in frequency regulation, solar smoothing and shifting, wind smoothing, and other applications. ${ }^{[217]}$ These batteries have lower energy density and charge-discharge efficiency than lithium-ion batteries, but are significantly cheaper. ${ }^{[218]}$

Lead is used in high voltage power cables as sheathing material to prevent water diffusion into insulation; this use is decreasing as lead is being phased out. ${ }^{[219]}$ Its use in solder for electronics is also being phased out by some countries to reduce the amount of environmentally hazardous waste. ${ }^{[220]}$ Lead is one of three metals used in the Oddy test for museum materials, helping detect organic acids, aldehydes, and acidic gases. ${ }^{[221][222]}$

$\mathbf{1 3}$ of $\mathbf{2 3}$ | WikiJournal of Science

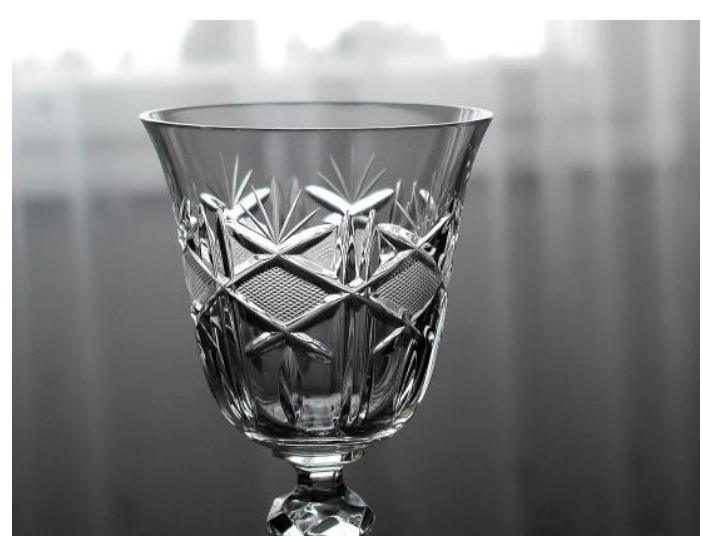

Figure 18 | Lead glass

Paolo Neo, public domain

\section{Compounds}

Lead compounds are used as, or in, coloring agents, oxidants, plastic, candles, glass, and semiconductors. While lead paints are phased out in Europe and North America, they remain in use in less developed countries such as China ${ }^{[223]}$ or India. ${ }^{[224]}$ Lead-based coloring agents are used in ceramic glazes and glass, especially for red and yellow shades. ${ }^{[225]}$ Lead tetraacetate and lead dioxide are used as oxidizing agents in organic chemistry. Lead is frequently used in the polyvinyl chloride coating of electrical cords. ${ }^{[226][227]}$ It can be used to treat candle wicks to ensure a longer, more even burn. Because of its toxicity, European and North American manufacturers use alternatives such as zinc.[228][229] Lead glass is composed of $12-28 \%$ lead oxide, changing its optical characteristics and reducing the transmission of ionizing radiation. ${ }^{[230]}$ Lead-based semiconductors such as lead telluride and lead selenide are used in photovoltaic cells and infrared detectors. ${ }^{[231]}$

\section{Biological effects}

Lead has no confirmed biological role. ${ }^{[232]}$ Its prevalence in the human body -at an adult average of $120 \mathrm{mg}^{[\mathrm{s}]}$ is nevertheless exceeded only by zinc $(2500 \mathrm{mg})$ and iron $(4000 \mathrm{mg})$ among the heavy metals. ${ }^{[234]}$ Lead salts are very efficiently absorbed by the body. ${ }^{[235]} \mathrm{A}$ small amount of lead (1\%) is stored in bones; the rest is excreted in urine and feces within a few weeks of exposure. Only about a third of lead is excreted by a child. ${ }^{[236]}$ Continual exposure may result in the bioaccumulation of lead. ${ }^{[236]}$

\section{Toxicity}

Lead is a highly poisonous metal (whether inhaled or swallowed), affecting almost every organ and system in the human body. ${ }^{[237]}$ At airborne levels of $100 \mathrm{mg} / \mathrm{m}^{3}$, it 
is immediately dangerous to life and health. ${ }^{[238]}$ Most ingested lead is absorbed into the bloodstream. ${ }^{[239]}$ The primary cause of its toxicity is its predilection for interfering with the proper functioning of enzymes. It does so by binding to the sulfhydryl groups found on many enzymes, ${ }^{[240]}$ or mimicking and displacing other metals which act as cofactors in many enzymatic reactions. ${ }^{[241]}$ Among the essential metals that lead interacts with are calcium, iron, and zinc. ${ }^{[242]} \mathrm{High}$ levels of calcium and iron tend to provide some protection from lead poisoning; low levels cause increased susceptibility. ${ }^{[235]}$

\section{Effects}

Lead can cause severe damage to the brain and kidneys and, ultimately, death. By mimicking calcium, lead can cross the blood-brain barrier. It degrades the myelin sheaths of neurons, reduces their numbers, interferes with neurotransmission routes, and decreases neuronal growth. ${ }^{[240]}$ In the human body, lead inhibits porphobilinogen synthase and ferrochelatase, preventing both porphobilinogen formation and the incorporation of iron into protoporphyrin IX, the final step in heme synthesis. This causes ineffective heme synthesis and microcytic anemia. ${ }^{[243]}$

Symptoms of lead poisoning include nephropathy, colic-like abdominal pains, and possibly weakness in the fingers, wrists, or ankles. Small blood pressure increases, particularly in middleaged and older people, may be apparent and can cause anemia. Several studies, mostly cross-sectional, found an association between increased lead exposure and decreased heart rate variability. ${ }^{[244]}$ In pregnant women, high levels of exposure to lead may cause miscarriage. Chronic, high-level exposure has been shown to reduce fertility in males. ${ }^{[245]}$

In a child's developing brain, lead interferes with synapse formation in the cerebral cortex, neurochemical development (including that of neurotransmitters), and the organization of ion channels. ${ }^{[246]}$ Early childhood exposure has been linked with an increased risk of sleep disturbances and excessive daytime sleepiness in later childhood. ${ }^{[27]}$ High blood levels are associated with delayed puberty in girls. ${ }^{[248]}$ The rise and fall in exposure to airborne lead from the combustion of tetraethyl lead in gasoline during the 20th century has been linked with historical increases and decreases in crime levels, a hypothesis which is not universally accepted. ${ }^{[249]}$

\section{Symptoms of}

\section{Lead poisoning}

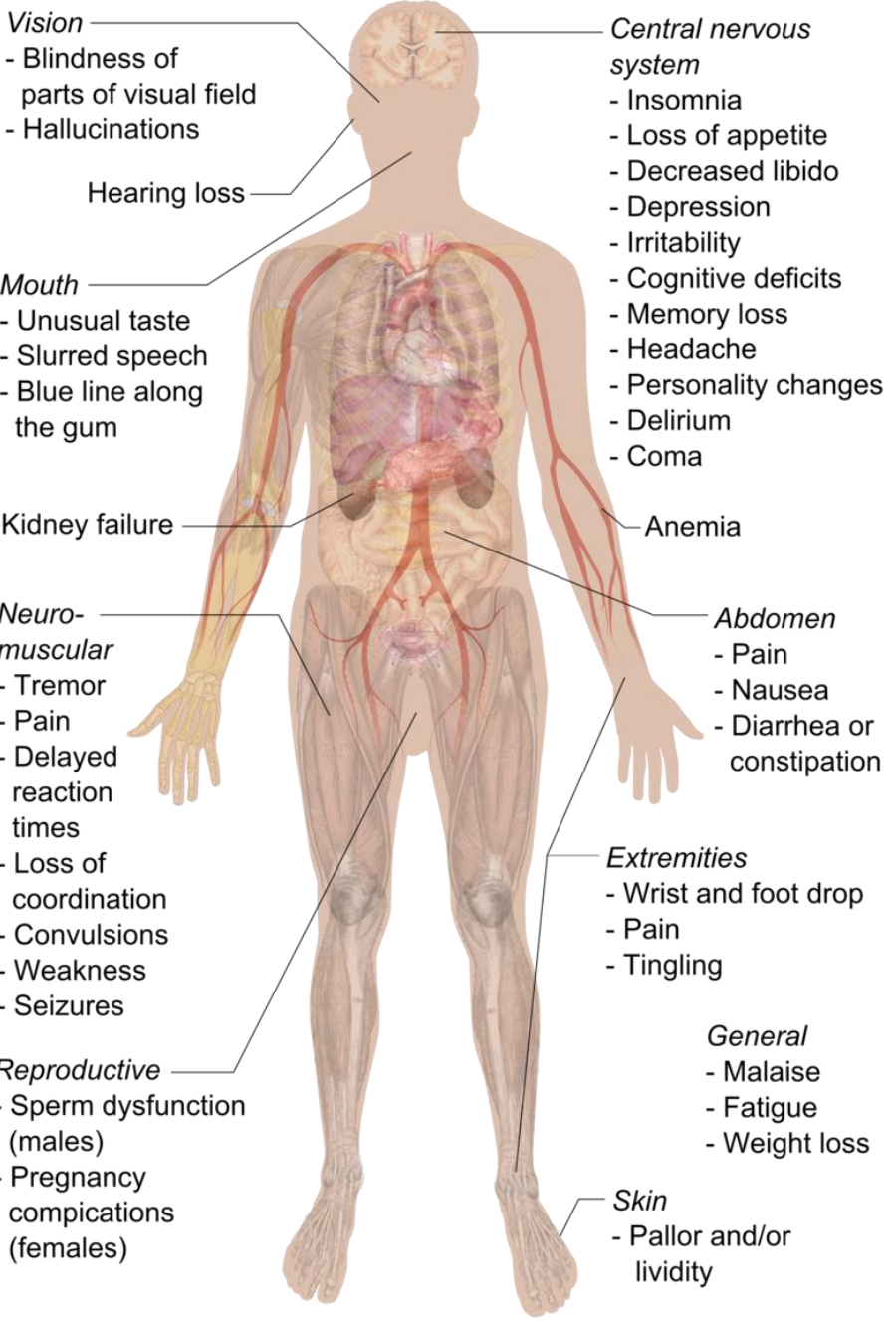

Figure 19 | Symptoms of lead poisoning Mikael Häggström, public domain

\section{Exposure sources}

Lead exposure is a global issue since lead mining and smelting, and battery manufacturing/disposal/recycling, are common in many countries. Lead enters the body via inhalation, ingestion, or skin absorption. Almost all inhaled lead is absorbed into the body; for ingestion, the rate is $20-70 \%$, with children absorbing a higher percentage than adults. ${ }^{[250]}$

Poisoning typically results from ingestion of food or water contaminated with lead, and less commonly after accidental ingestion of contaminated soil, dust, or leadbased paint. ${ }^{[251]}$ Seawater products can contain lead if affected by nearby industrial waters. ${ }^{[252]}$ Fruit and vegetables can be contaminated by high levels of lead in the soils they were grown in. Soil can be contaminated 


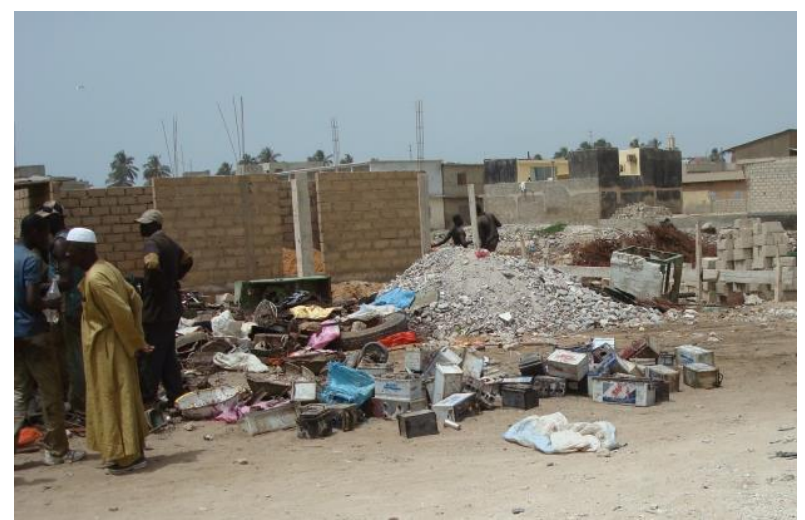

Figure 20 | Battery collection site in Dakar, Senegal, where at least 18 children died of lead poisoning in 2008

J Caravanos, CC-BY-SA 4.0

through particulate accumulation from lead in pipes, lead paint, and residual emissions from leaded gasoline. ${ }^{[253]}$

The use of lead for water pipes is problematic in areas with soft or acidic water. ${ }^{[254]}$ Hard water forms insoluble layers in the pipes whereas soft and acidic water dissolves the lead pipes. ${ }^{[255]}$ Dissolved carbon dioxide in the carried water may result in the formation of soluble lead bicarbonate; oxygenated water may similarly dissolve lead as lead(II) hydroxide. ${ }^{[256]}$ Drinking such water, over time, can cause health problems due to the toxicity of the dissolved lead. The harder the water the more calcium bicarbonate and sulfate it will contain, and the more the inside of the pipes will be coated with a protective layer of lead carbonate or lead sulfate. ${ }^{[257]}$

Ingestion of applied lead-based paint is the major source of exposure for children: a direct source is chewing on old painted window sills. Alternatively, as the applied dry paint deteriorates, it peels, is pulverized into dust, and then enters the body through hand-to-mouth contact or contaminated food, water, or alcohol. Ingesting certain home remedies may result in exposure to lead or its compounds. ${ }^{[258]}$

Inhalation is the second major exposure pathway, affecting smokers and especially workers in lead-related occupations. ${ }^{[239]}$ Cigarette smoke contains, among other toxic substances, radioactive lead-210. ${ }^{[259]}$

Skin exposure may be significant for people working with organic lead compounds. The rate of skin absorption is lower for inorganic lead. [260]

\section{Treatment}

Treatment for lead poisoning normally involves the administration of dimercaprol and succimer. ${ }^{[261]}$ Acute cases may require the use of disodium calcium edetate, the calcium chelate of the disodium salt of ethylenediaminetetraacetic acid (EDTA). It has a greater affinity for lead than calcium, with the result that lead chelate is formed by exchange and excreted in the urine, leaving behind harmless calcium. ${ }^{[262]}$

\section{Environmental effects}

The extraction, production, use, and disposal of lead and its products have caused significant contamination of the Earth's soils and waters. Atmospheric emissions of lead were at their peak during the Industrial Revolution, and the leaded gasoline period in the second half of the twentieth century. Lead releases originate from natural sources (i.e., concentration of the naturally occurring lead), industrial production, incineration and recycling, and mobilization of previously buried lead. ${ }^{[263]}$ Elevated concentrations of lead persist in soils and sediments in post-industrial and urban areas; industrial emissions, including those arising from coal burning, ${ }^{[264]}$ continue in many parts of the world, particularly in the developing countries. ${ }^{[265]}$

Lead can accumulate in soils, especially those with a high organic content, where it remains for hundreds to thousands of years. Environmental lead can compete with other metals found in and on plants surfaces potentially inhibiting photosynthesis and at high enough concentrations, negatively affecting plant growth and survival. Contamination of soils and plants can allow lead to ascend the food chain affecting microorganisms and animals. In animals, lead exhibits toxicity in many organs, damaging the nervous, renal, reproductive, hematopoietic, and cardiovascular systems after ingestion, inhalation, or skin absorption. ${ }^{[266]}$ Fish uptake lead from both water and sediment; ${ }^{[267]}$ bioaccumulation in the food chain poses a hazard to fish, birds, and sea mammals. ${ }^{[268]}$

Antropogenic lead includes lead from shot and sinkers. These are among the most potent sources of lead contamination along with lead production sites. ${ }^{[269]}$ Lead was banned for shot and sinkers in the United States in $2017,{ }^{[270]}$ although that ban was only effective for a month, ${ }^{[271]}$ and a similar ban is being considered in the European Union. ${ }^{[272]}$

Analytical methods for the determination of lead in the environment include spectrophotometry, X-ray fluorescence, atomic spectroscopy and electrochemical methods. A specific ion-selective electrode has been developed based on the ionophore S, S'-methylenebis(N,Ndiisobutyldithiocarbamate). ${ }^{[273]}$ An important biomarker assay for lead poisoning is $\delta$-aminolevulinic acid levels in plasma, serum, and urine. ${ }^{[274]}$ 


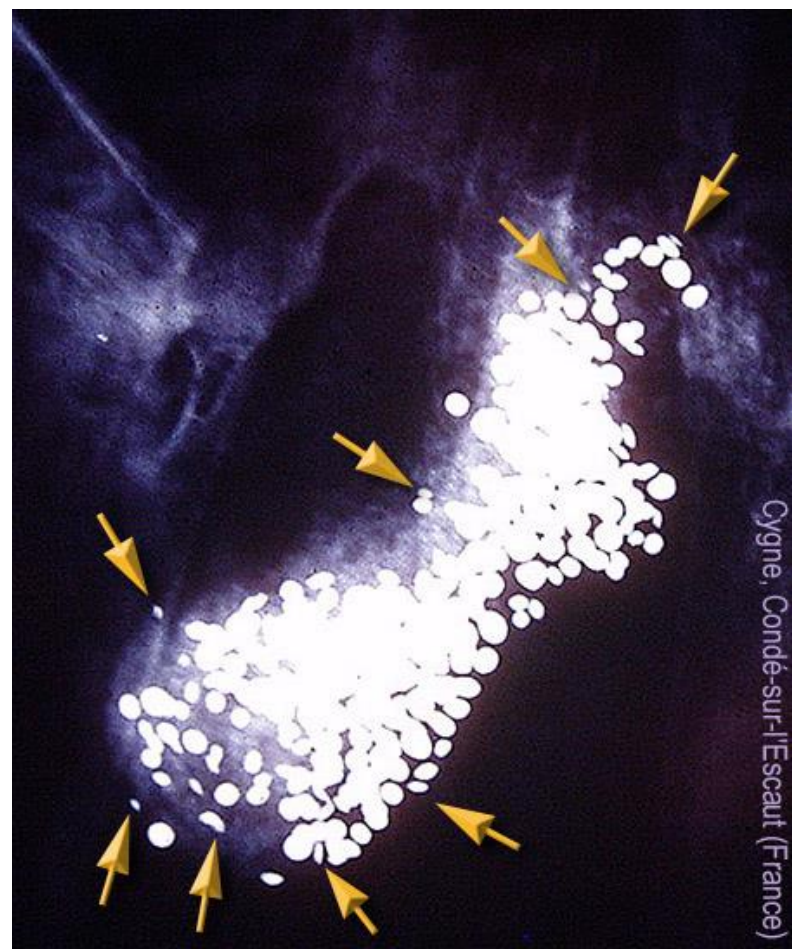

Figure 21 | Radiography of a swan found dead in Conde-surI'Escaut (northern France), highlighting lead shot. There are hundreds of lead pellets; a dozen is enough to kill an adult swan within a few days. Such bodies are sources of environmental contamination by lead.

Rafael Mateo, CC-BY-SA 3.0

\section{Restriction and remediation}

By the mid-1980s, there was significant decline in the use of lead in industry. In the United States, environmental regulations reduced or eliminated the use of lead in non-battery products, including gasoline, paints, solders, and water systems. Particulate control devices were installed in coal-fired power plants to capture lead emissions. ${ }^{[264]}$ Lead use was further curtailed by the European Union's 2003 Restriction of Hazardous Substances Directive. ${ }^{[275]}$ A large drop in lead deposition occurred in the Netherlands after the 1993 national ban on use of lead shot for hunting and sport shooting: from 230 tonnes in 1990 to 47.5 tonnes in 1995 [276] $^{\text {[27) }}$

In the United States, the permissible exposure limit for lead in the workplace, comprising metallic lead, inorganic lead compounds, and lead soaps, was set at 50 $\mathrm{\mu g} / \mathrm{m}^{3}$ over an 8-hour workday, and the blood lead level limit at $5 \mu \mathrm{g}$ per $100 \mathrm{~g}$ of blood in 2012. ${ }^{[277]}$ Lead may still be found in harmful quantities in stoneware, ${ }^{[278]} \mathrm{vi}$ ny ${ }^{[279]}$ (such as that used for tubing and the insulation of electrical cords), and Chinese brass. ${ }^{[t]}$ Old houses may still contain lead paint. ${ }^{[279]}$ White lead paint has been withdrawn from sale in industrialized countries, but specialized uses of other pigments such as yellow lead chromate remain. ${ }^{[168]}$ Stripping old paint by sanding produces dust which can be inhaled. ${ }^{[281]}$ Lead abatement programs have been mandated by some authorities in properties where young children live. ${ }^{[282]}$

Lead waste, depending of the jurisdiction and the nature of the waste,
NFPA 704

fire diamond

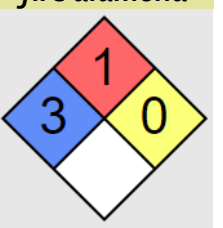

Figure 22 |

Fire diamond for lead granules may be treated as household waste (in order to facilitate lead abatement activities), ${ }^{[283]}$ or potentially hazardous waste requiring specialized treatment or storage. ${ }^{[284]}$ Lead is released to the wildlife in shooting places and a number of lead management practices, such as stewardship of the environment and reduced public scrutiny, have been developed to counter the lead contamination. ${ }^{[285]}$ Lead migration can be enhanced in acidic soils; to counter that, it is advised soils be treated with lime to neutralize the soils and prevent leaching of lead. ${ }^{[286]}$

Research has been conducted on how to remove lead from biosystems by biological means: Fish bones are being researched for their ability to bioremediate lead in contaminated soil. ${ }^{[287][288]}$ The fungus Aspergillus versicoloris effective at removing lead ions. ${ }^{[289]}$ Several bacteria have been researched for their ability to remove lead from the environment, including the sulfatereducing bacteria Desulfovibrio and Desulfotomaculum, both of which are highly effective in aqueous solutions. ${ }^{[290]}$

\section{Acknowledgements}

I would like to thank the many Wikipedia editors who commented on, copyedited, contributed to, or otherwise helped to improve this article, including those who assisted at the Wikipedia featured article candidacy: Graeme Bartlett, Jimfbleak, Sandbh, Nergaal, DePiep, John, Cas Liber, Axl, Double sharp, Smurrayinchester, edwininlondon, and Parcly Taxel. I would also like to thank the reviewers who provided journal peer reviews: Marshall Sumter, Jaclyn Catalano, an anonymous reviewer, and Robert M. Gogal Jr.

\section{Notes}

a. About $10 \%$ of the lanthanide contraction has been attributed to relativistic effects. ${ }^{[2]}$

b. The tetrahedral allotrope of tin is called $\alpha$ - or gray tin and is stable only at or below $13.2^{\circ} \mathrm{C}\left(55.8^{\circ} \mathrm{F}\right)$. The stable form of tin above this temperature is called $\beta$ - or white tin and has a distorted face centered cubic (tetragonal) structure which can be derived by compressing the tetrahedra of gray tin along their cubic axes. White tin effectively has a structure intermediate 
between the regular tetrahedral structure of gray tin, and the regular face centered cubic structure of lead, consistent with the general trend of increasing metallic character going down any representative group. ${ }^{[8]}$

c. A quasicrystalline thin-film allotrope of lead, with pentagonal symmetry, was reported in 2013. The allotrope was obtained by depositing lead atoms on the surface of an icosahedral silver-indium-ytterbium quasicrystal. Its conductivity was not recorded. ${ }^{[9][10]}$

d. Diamond cubic structures with lattice parameters around the lattice parameter of silicon exists both in thin lead and tin films, and in massive lead and tin, freshly solidified in vacuum of $\approx 5 \times 10^{-6}$ Torr. Experimental evidence for almost identical structures of at least three oxide types is presented, demonstrating that lead and tin behave like silicon not only in the initial stages of crystallization, but also in the initial stages of oxidation. ${ }^{[11]}$

e. Malleability describes how easily it deforms under compression, whereas ductility means its ability to stretch.

f. British English: to go down like a lead balloon.

g. A (wet) finger can be dipped into molten lead without risk of a burning injury. ${ }^{[25]}$

h. An even number of either protons or neutrons generally increases the nuclear stability of isotopes, compared to isotopes with odd numbers. No elements with odd atomic numbers have more than two stable isotopes; even-numbered elements have multiple stable isotopes, with tin (element 50 ) having the highest number of isotopes of all elements, ten. ${ }^{[29]}$ See Even and odd atomic nuclei for more details.

i. The half-life found in the experiment was $1.9 \times 10^{19}$ years. ${ }^{[32]} \mathrm{A}$ kilogram of natural bismuth would have an activity value of approximately 0.003 becquerels (decays per second). For comparison, the activity value of natural radiation in the human body is around 65 becquerels per kilogram of body weight ( 4500 becquerels on average). ${ }^{[33]}$

j. Lead-205 decays solely via electron capture, which means when there are no electrons available and lead is fully ionized with all 82 electrons removed it cannot decay. Fully ionized thallium-205, the isotope lead-205 would decay to, becomes unstable and can decay into a bound state of lead-205. ${ }^{[43]}$

k. Abundances in the source are listed relative to silicon rather than in perparticle notation. The sum of all elements per $10^{6}$ parts of silicon is $2.6682 \times 10^{10}$ parts; lead comprises 3.258 parts.

I. Elemental abundance figures are estimates and their details may vary from source to source. $[107]$

m. The fact that Julius Caesar fathered only one child, as well as the alleged sterility of his successor, Caesar Augustus, have been attributed to lead poisoning. ${ }^{[136]}$

n. The inscription reads: "Made when the Emperor Vespasianwas consul for the ninth term and the Emperor Titus was consul for the seventh term, when Gnaeus lulius Agricola was imperial governor (of Britain)."

o. Gaseous by-product of the coking process, containing carbon monoxide, hydrogen and methane; used as a fuel.

p. California began banning lead bullets for hunting on that basis in July 2015. ${ }^{[199]}$

q. For example, a firm "...producing quality [lead] garden ornament from our studio in West London for over a century".[206]

r. See ${ }^{[216]}$ for details on how a lead-acid battery works.

s. Rates vary greatly by country. ${ }^{[233]}$

t. An alloy of brass (copper and zinc) with lead, iron, tin, and sometimes antimony. ${ }^{[280]}$

\section{References}

1. Lide 2005, p. 10-179

2. Pyykko 1988, pp. 563-94.

3. Norman 1996, p. 36.

4. Greenwood \& Earnshaw 1998, pp. 226-27, 374

5. Christensen 2002, p. 867.

6. Slater 1964.

7. Considine \& Considine 2013, pp. 501, 2970.

8. Parthe 1964, p. 13.

9. Sharma et al. 2013

10. Sharma et al. 2014, p. 174710.

11. Peneva, Djuneva \& Tsukeva 1981.

12. Greenwood \& Earnshaw 1998, p. 372.

13. Greenwood \& Earnshaw 1998, pp. 372-73.

14. Meija et al. 2016.

15. Thornton, Rautiu \& Brush 2001, p. 6

16. Lide 2005 , pp. $12-35,12-40$
17. Brenner 2003, p. 396.

18. Jones 2014 , p. 42

19. Lide 2005, pp. 4-13, 4-21, 4-33.

20. Vogel \& Achilles 2013, p. 8.

21. Anderson 1869, pp. 341-43.

22. Gale \& Totemeier 2003, pp. 15-2-15-3.

23. Thornton, Rautiu \& Brush 2001, p. 8.

24. Lide 2005 , p. $12-219$.

25. Willey 1999

26. Lide 2005 , p. $12-45$.

27. Blakemore 1985, p. 272.

28. Webb, Marsiglio \& Hirsch 2015.

29. IAEA - Nuclear Data Section 2017.

30. University of California Nuclear Forensic Search Project.

31. Stone 1997

32. Marcillac et al. 2003, pp. 876-78.

33. World Nuclear Association 2015.

34. Beeman et al. 2013.

35. Committee on Evaluation of EPA Guidelines for Exposure to Naturally Occurring Radioactive Materials et al. 1999, pp. 26, 30-32.

36. Smirnov, Borisevich \& Sulaberidze 2012

37. Greenwood \& Earnshaw 1998, p. 368.

38. Levin 2009, pp. 40-41.

39. Webb 2000 , p. 115.

40. Wrackmeyer \& Horchler 1990.

41. Cangelosi \& Pecoraro 2015

42. Fiorini 2010, pp. 7-8.

43. Takahashi et al. 1987.

44. Thurmer, Williams \& Reutt-Robey 2002, pp. 2033-35

45. Tetreault, Sirois \& Stamatopoulou 1998, pp. 17-32.

46. Thornton, Rautiu \& Brush 2001, pp. 10-11.

47. Greenwood \& Earnshaw 1998, p. 373.

48. Bretherick 2016, p. 1442.

49. Harbison, Bourgeois \& Johnson 2015, p. 132.

50. Greenwood \& Earnshaw 1998, p. 374.

51. Thornton, Rautiu \& Brush 2001, pp. 11-12.

52. Polyanskiy 1986, p. 20

53. Kaupp 2014, pp. 9-10.

54. Dieter \& Watson 2009, p. 509.

55. Hunt 2014, p. 215

56. King 1995, pp. 43-63.

57. Bunker \& Casey 2016, p. 89.

58. Whitten, Gailey \& David 1996, pp. 904-5.

59. Greenwood \& Earnshaw 1998, p. 384.

60. Greenwood \& Earnshaw 1998, p. 387.

61. Greenwood \& Earnshaw 1998, p. 389.

62. Zuckerman \& Hagen 1989, p. 426

63. Funke 2013.

64. Greenwood \& Earnshaw 1998, p. 382.

65. Bharara \& Atwood 2006, p. 4

66. Greenwood \& Earnshaw 1998, p. 388.

67. Toxicological Profile for Lead 2007, p. 277.

68. Downs \& Adams 2017, p. 1128.

69. Brescia 2012, p. 234

70. Macintyre 1992, p. 3775.

71. Silverman 1966, pp. 2067-69.

72. Greenwood \& Earnshaw 1998, p. 381.

73. Yong, Hoffmann \& Fassler 2006, pp. 4774-78.

74. Becker et al. 2008, pp. 9965-78.

75. Mosseri, Henglein \& Janata 1990, pp. 2722-26

76. Konu \& Chivers 2011, p. 391-92.

77. Hadlington 2017, p. 59

78. Greenwood \& Earnshaw 1998, pp. 384-86.

79. Rohr 2017.

80. Alsfasser 2007, pp. 261-63.

81. Greenwood \& Earnshaw 1998, p. 393.

82. Stabenow, Saak \& Weidenbruch 2003.

83. Polyanskiy 1986, p. 43.

84. Greenwood \& Earnshaw 1998, p. 404.

85. Wiberg, Wiberg \& Holleman 2001, p. 918.

86. CTI Reviews 2016, pp. 228-229.

87. Toxicological Profile for Lead 2007, p. 287

88. Polyanskiy 1986, p. 44.

89. Windholz 1976.

90. Zyka 1966, p. 569

91. Lodders 2003, pp. 1222-23.

92. Roederer et al. 2009, pp. 1963-80. 
93. Lochner, Rohrbach \& Cochrane 2005, p. 12.

94. Lodders 2003, p. 1224

95. Burbidge et al. 1957, pp. 608-615.

96. Burbidge et al. 1957, p. 551.

97. Burbidge et al. 1957, pp. 608-609.

98. Burbidge et al. 1957, p. 553.

99. Frebel 2015, pp. 114-15.

100. Burbidge et al. 1957, pp. 608-610.

101. Burbidge et al. 1957, p. 595.

102. Burbidge et al. 1957 , p. 596

103. Burbidge et al. 1957, pp. 582, 609-615.

104. Langmuir \& Broecker 2012, pp. 183-184.

105. Davidson et al. 2014, pp. 4-5.

106. Emsley 2011, pp. 286, passim.

107. Cox 1997, p. 182.

108. Davidson et al. 2014, p. 4

109. United States Geological Survey 2017, p. 97.

110. Rieuwerts 2015 , p. 225.

111. Merriam-Webster.

112. Kroonen 2013, *lauda-.

113. Nikolayev 2012

114. Kroonen 2013, *bliwa- 2.

115. Kroonen 2013 , *laidijan-

116. Hong et al. 1994, pp. 1841-43.

117. Rich 1994, p. 4.

118. Winder 1993b.

119. History of Cosmetics.

120. Yu \& Yu 2004, p. 26.

121. Toronto museum explores 2003.

122. Bisson \& Vogel 2000, p. 105.

123. Lead sling bullet.

124. Rich 1994, p. 5.

125. United States Geological Survey 1973.

126. de Callatay 2005, pp. 361-72.

127. Eschnaver \& Stoeppler 1992, pp. 58.

128. Rich 1994, p. 6.

129. Thornton, Rautiu \& Brush 2001, pp. 179-84.

130. Bisel \& Bisel 2002, pp. 459-60.

131. Retief \& Cilliers 2006, pp. 149-51.

132. Grout 2017.

133. Hodge 1981, pp. 486-91.

134. Gilfillan 1965, pp. 53-60.

135. Nriagu 1983, pp. 660-63.

136. Frankenburg 2014, p. 16

137. Scarborough 1984.

138. Waldron 1985, pp. 107-08.

139. Reddy \& Braun 2010, p. 1052.

140. Delile et al. 2014, pp. 6594-99.

141. Finger 2006, p. 184.

142. Lewis 1985, p. 15.

143. Thornton, Rautiu \& Brush 2001, p. 183.

144. Polyanskiy 1986, p. 8.

145. Thomson 1830, p. 74.

146. Oxford English Dictionary, surma.

147. Vasmer 1950, сурьма.

148. Winder 1993a.

149. Rich 1994, p. 7.

150. Kellett 2012, pp. 106-07.

151. Rich 1994, p. 8.

152. Cotnoir 2006, p. 35.

153. Samson 1885 , p. 388

154. Sinha et al. 1993.

155. Ramage 1980, p. 8.

156. Tungate 2011 , p. 14

157. Donnelly 2014, pp. 171-172.

158. Ashikari 2003, p. 65.

159. Nakashima et al. 1998 , p. 59.

160. Rabinowitz 1995, p. 66

161. Gill \& Libraries Board of South Australia 1974, p. 69.

162. Bisson \& Vogel 2000, p. 85.

163. Bisson \& Vogel 2000, pp. 131-32.

164. Lead mining.

165. Rich 1994, p. 11

166. Riva et al. 2012, pp. 11-16.

167. Hernberg 2000, pp. 246.

168. Crow 2007.

169. Markowitz \& Rosner 2000, p. 37.
170. More et al. 2017

171. American Geophysical Union 2017.

172. Centers for Disease Control and Prevention 1997.

173. Rich 1994, p. 117.

174. Rich 1994, p. 17.

175. Rich 1994, pp. 91-92.

176. United States Geological Survey 2005.

177. Zhang et al. 2012, pp. 2261-73.

178. Tolliday 2014.

179. Guberman 2016.

180. Graedel 2010.

181. Thornton, Rautiu \& Brush 2001, p. 56

182. Davidson et al. 2014, p. 6.

183. Davidson et al. 2014, p. 17.

184. Thornton, Rautiu \& Brush 2001, p. 51.

185. Davidson et al. 2014, pp. 11-12.

186. Thornton, Rautiu \& Brush 2001, pp. 51-52.

187. Davidson et al. 2014 , p. 25.

188. Primary Lead Refining.

189. Pauling 1947.

190. Davidson et al. 2014, p. 34

191. Davidson et al. 2014, p. 23.

192. Thornton, Rautiu \& Brush 2001, pp. 52-53.

193. United States Environmental Protection Agency 2010, p. 1.

194. Thornton, Rautiu \& Brush 2001, p. 57.

195. Thornton, Rautiu \& Brush 2001, pp. 57-58.

196. Street \& Alexander 1998, p. 181.

197. Evans 1908, pp. 133-79.

198. Baird \& Cann 2012, pp. 537-38, 543-47.

199. California Department of Fish and Wildlife.

200. Parker 2005, pp. 194-95.

201. Krestovnikoff \& Halls 2006, p. 70

202. Street \& Alexander 1998, p. 182.

203. Jensen 2013 , p. 136.

204. Think Lead research.

205. Weatherings to Parapets.

206. Lead garden ornaments 2016.

207. Putnam 2003, p. 216.

208. Copper Development Association.

209. Rich 1994, p. 101

210. Guruswamy 2000, p. 31.

211. Audsley 1965, pp. 250-51.

212. Palmieri 2006, pp. 412-13.

213. National Council on Radiation Protection and Measurements 2004, pp. 16.

214. Thornton, Rautiu \& Brush 2001, p. 7.

215. Tucek, Carlsson \& Wider 2006, p. 1590.

216. Progressive Dynamics, Inc.

217. Olinsky-Paul 2013.

218. Gulbinska 2014.

219. Rich 1994, pp. 133-34.

220. Zhao 2008 , p. 440

221. Beiner et al. 2015.

222. Szczepanowska 2013, pp. 84-85.

223. Insight Explorer \& IPEN 2016.

224. Singh 2017.

225. Burleson 2001, pp. 23.

226. Zweifel 2009, p. 438

227. Wilkes et al. 2005, p. 106.

228. Randerson 2002.

229. Nriagu \& Kim 2000, pp. 37-41.

230. Amstock 1997, pp. 116-19.

231. Rogalski 2010, pp. 485-541.

232. Emsley 2011, p. 280.

233. World Health Organization 2000, pp. 149-53.

234. Emsley 2011, p. 280, 621, 255.

235. Luckey \& Venugopal 1979, pp. 177-78.

236. Toxic Substances Portal.

237. United States Food and Drug Administration 2015, p. 42.

238. National Institute for Occupational Safety and Health.

239. Occupational Safety and Health Administration.

240. Rudolph et al. 2003, p. 369.

241. Dart, Hurlbut \& Boyer-Hassen 2004, p. 1426

242. Kosnett 2006, p. 238.

243. Cohen, Trotzky \& Pincus 1981.

244. Navas-Acien 2007.

245. Sokol 2005, p. 133, passim

246. Mycyk, Hryhorczuk \& Amitai 2005, p. 462. 
247. Liv et al. 2015, pp. 1869-74

248. Schoeters et al. 2008, pp. 168-75.

249. Casciani 2014

250. Tarrago 2012, p. 16.

251. Toxicological Profile for Lead 2007, p. 4

252. Bremner 2002, p. 101.

253. Agency for Toxic Substances and Disease Registry.

254. Thornton, Rautiu \& Brush 2001, p. 17.

255. Moore 1977, pp. 109-15.

256. Polyanskiy 1986, p. 32.

257. Wiberg, Wiberg \& Holleman 2001, p. 914.

258. Tarrago 2012, p. 11.

259. Centers for Disease Control and Prevention 2015.

260. Wani, Ara \& Usman 2015, pp. 57, 58.

261. Prasad 2010, pp. 651-52.

262. Masters, Trevor \& Katzung 2008, pp. 481-83.

263. United Nations Environment Programme 2010, p. 4.

264. Trace element emission 2012.

265. United Nations Environment Programme 2010, p. 6.

266. Assi et al. 2016.

267. World Health Organization 1995.

268. UK Marine SACs Project 1999.

269. United Nations Environment Programme 2010, p. 9.

270. McCoy 2017.

271. Cama 2017.

272. Layton 2017.

273. Hauser 2017, pp. 49-60.

274. Lauwerys \& Hoet 2001, pp. 115, 116-117.

275. Petzel, Juuti \& Sugimoto 2004, pp. 122-124.

276. Deltares \& Netherlands Organisation for Applied Scientific Research 2016.

277. Agency for Toxic Substances and Disease Registry 2017.

278. Grandjean 1978, pp. 303-21.

279. Levin et al. 2008, p. 1288

280. Duda 1996, p. 242.

281. Marino et al. 1990, pp. 1183-85.

282. Schoch 1996, p. 111.

283. United States Environmental Protection Agency 2000.

284. Lead in Waste 2016.

285. United States Environmental Protection Agency 2005, p. I-1.

286. United States Environmental Protection Agency 2005, p. III-5-III-6.

287. Freeman 2012, pp. a20-a21.

288. Young 2012.

289. Acton 2013, pp. 94-95.

290. Park et al. 2011, pp. 162-74.

\section{Bibliography}

- Acton, Q. A., ed. (2013). Issues in Global Environment-Pollution and Waste Management: 2012 Edition. ScholarlyEditions. ISBN 978-1-4816-4665-9.

- Agency for Toxic Substances and Disease Registry. "Information for the Community: Lead Toxicity" (MP4 webcast, 82 MB). Retrieved 11 February 2017.

- Agency for Toxic Substances and Disease Registry (2017). "Lead Toxicity. What Are U.S. Standards for Lead Levels?". Retrieved 12 June 2018.

- Alsfasser, R. (2007). Moderne anorganische Chemie [Modern inorganic chemistry] (in German). Walter de Gruyter. ISBN 978-3-11-019060-1.

- American Geophysical Union (2017). "Human Activity Has Polluted European Air for 2000 Years". Eos Science News.

- Amstock, J. S. (1997). Handbook of Glass in Construction. McGraw-Hill Professional. ISBN 978-0-07-001619-4.

- Anderson, J. (1869). "Malleability and ductility of metals". Scientific American 21 (22): 341-43. doi:10.1038/scientificamerican11271869-341.

- Ashikari, M. (2003). "The memory of the women's white faces: Japaneseness and the ideal image of women". Japan Forum 15(1): 55-79. doi:10.1080/0955580032000077739.

- Assi, M. A.; Hezmee, M. N. M.; Haron, A. W.; Sabri, M. Yu.; Rajion, M. A. (2016). "The detrimental effects of lead on human and animal health". Veterinary World 9 (6): 660-671. doi:10.14202/vetworld.2016.660-671. ISSN 09728988.

- Audsley, G. A. (1965). The Art of Organ Building. 2. Courier. ISBN 978-0486-21315-6.

- Baird, C.; Cann, N. (2012). Environmental Chemistry (5th ed.). W. H. Freeman and Company. ISBN 978-1-4292-7704-4.
- Becker, M.; Forster, C.; Franzen, C. et al. (2008). "Persistent radicals of trivalent tin and lead". Inorganic Chemistry 47 (21): 9965-78. doi:10.1021/ic801198p. PMID 18823115.

- Beeman, J. W.; Bellini, F.; Cardani, L. et al. (2013). "New experimental limits on the $\alpha$ decays of lead isotopes". European Physical Journal A 49 (50). doi:10.1140/epja/i2013-13050-7.

- Beiner, G. G.; Lavi, M.; Seri, H. et al. (2015). "Oddy Tests: Adding the Analytical Dimension". Collection Forum 29 (1-2): 22-36. doi:10.14351/0831-4985-29.1.22. ISSN 0831-4985.

- Bharara, M. S.; Atwood, D. A. (2006). Lead: Inorganic Chemistry. doi:10.1002/0470862106.ia118.

- Bisel, S. C.; Bisel, J. F. (2002). "Health and nutrition at Herculaneum". In Jashemski, W. F.; Meyer, F. G. The Natural History of Pompeii. Cambridge University Press. pp. 451-75. ISBN 978-0-521-80054-9.

- Bisson, M. S.; Vogel, J. O. (2000). Ancient African Metallurgy: The Sociocultural Context. Rowman \& Littlefield. ISBN 978-0-7425-0261-1.

- Blakemore, J. S. (1985). Solid State Physics. Cambridge University Press. ISBN 978-0-521-31391-9.

- Burleson, M. (2001). The Ceramic Glaze Handbook: Materials, Techniques, Formulas. New York, NY: Sterling.

- Bremner, H. A. (2002). Safety and Quality Issues in Fish Processing. Elsevier. ISBN 978-1-85573-678-8.

- Brenner, G. A. (2003). Webster's New World American Idioms Handbook. John Wiley \& Sons. ISBN 978-0-7645-2477-6.

- Brescia, F. (2012). Fundamentals of Chemistry: A Modern Introduction. Elsevier. ISBN 978-0-323-14231-1.

- Bretherick, L. (2016). Bretherick's Handbook of Reactive Chemical Hazards. Elsevier. ISBN 978-1-4831-6250-8.

- Bunker, B. C.; Casey, W. H. (2016). The Aqueous Chemistry of Oxides. Oxford University Press. ISBN 978-0-19-938425-9.

- Burbidge, E. M.; Burbidge, G. R.; Fowler, W. A. et al. (1957). "Synthesis of the Elements in Stars" (PDF). Reviews of Modern Physics 29 (4): 547-654. doi:10.1103/RevModPhys.29.547.

- California Department of Fish and Wildlife. "Nonlead Ammunition in California". www. wildlife.ca.gov. Retrieved 17 May 2017.

- de Callatay, F. (2005). "The Graeco-Roman economy in the super long-run: Lead, copper, and shipwrecks". Journal of Roman Archaeology 18: 361-72. doi:10.1017/S104775940000742X.

- Cama, T. (2017). "Interior secretary repeals ban on lead bullets". The Hill. Retrieved 30 May 2018.

- Cangelosi, V. M.; Pecoraro, V. L. (2015). "Lead". In Roduner, E. Nanoscopic Materials: Size-Dependent Phenomena and Growth Principles. Royal Society of Chemistry. p. 843-875. ISBN 978-1-78262-494-3.

- Casciani, D. (2014). "Did removing lead from petrol spark a decline in crime?". BBC News. Retrieved 30 January 2017.

- Centers for Disease Control and Prevention (1997). "Update: blood lead levels--United States, 1991-1994". Morbidity and Mortality Weekly Report 46 (7): 141-146. ISSN 0149-2195. PMID 9072671.

- Centers for Disease Control and Prevention (2015). "Radiation and Your Health". Retrieved 28 February 2017.

- Christensen, N. E. (2002). "Relativistic Solid State Theory". In Schwerdtfeger, P. Relativistic Electronic Structure Theory - Fundamentals. Elsevier. pp. 867-68. doi:10.1016/s1380-7323(02)80041-3. ISBN 978-0-08054046-7.

- Cohen, A. R.; Trotzky, M. S.; Pincus, D. (1981). "Reassessment of the Microcytic Anemia of Lead Poisoning". Pediatrics 67 (6): 904-906. PMID 7232054.

- Committee on Evaluation of EPA Guidelines for Exposure to Naturally Occurring Radioactive Materials; Commission on Life Sciences; Division on Earth and Life Studies; National Research Council (1999). Evaluation of Guidelines for Exposures to Technologically Enhanced Naturally Occurring Radioactive Materials. National Academies Press. pp. 26, 30-32. ISBN 9780-309-58070-0.

- Considine, D. M.; Considine, G. D. (2013). Van Nostrand's Scientific Encyclopedia. Springer Science \& Business Media. ISBN 978-1-4757-69180 .

- Copper Development Association. "Leaded Coppers". copper.org. Retrieved 10 July 2016

- Cotnoir, B. (2006). The Weiser Concise Guide to Alchemy. Weiser Books. ISBN 978-1-57863-379-1.

- Cox, P. A. (1997). The Elements: Their Origin, Abundance and Distribution. Oxford University Press. ISBN 978-0-19-855298-7.

- Crow, J. M. (2007). "Why use lead in paint?". Chemistry World. Royal Society of Chemistry. Retrieved 22 February 2017.

- CTI Reviews (2016). Inorganic Chemistry: Chemistry, Inorganic chemistry. Cram101. ISBN 978-1-4784-5112-9. 
- Dart, R. C.; Hurlbut, K. M.; Boyer-Hassen, L. V. (2004). "Lead". In Dart, R. C. Medical Toxicology (3rd ed.). Lippincott Williams \& Wilkins. p. 1426. ISBN 978-0-7817-2845-4

- Davidson, A.; Ryman, J.; Sutherland, C. A.; et al. (2014). "Lead". Ullmann's Encyclopedia of Industrial Chemistry. doi:10.1002/14356007.a15_193.pub3. ISBN 978-3-527-30673-2.

- Delile, H.; Blichert-Toft, J.; Goiran, J.-P. et al. (2014). "Lead in ancient Rome's city waters". Proceedings of the National Academy of Sciences 111 (18): 6594-99. doi:10.1073/pnas.1400097111. ISSN 0027-8424. PMID 24753588. PMC 4020092.

- Deltares; Netherlands Organisation for Applied Scientific Research(2016). Lood en zinkemissies door jacht [Lead and zinc emissions from hunting] (PDF) (Report) (in Dutch). Retrieved 18 February 2017.

- Dieter, R. K.; Watson, R. T. (2009). "Transmetalation reactions producing organocopper compounds". In Rappoport, Z.; Marek, I. The Chemistry of Organocopper Compounds. 1. John Wiley \& Sons. pp. 443-526. ISBN 978-0470-77296-6.

- Donnelly, J. (2014). Deep Blue. Hachette Children's Group. ISBN 978-14449-2119-9.

- Downs, A. J.; Adams, C. J. (2017). The Chemistry of Chlorine, Bromine, lodine and Astatine: Pergamon Texts in Inorganic Chemistry. Elsevier. ISBN 978-14831-5832-7.

- Duda, M. B. (1996). Traditional Chinese Toggles: Counterweights and Charms. Editions Didier Millet. ISBN 978-981-4260-61-9.

- Ede, A.; Cormack, L. B. (2016). A History of Science in Society, Volume I: From the Ancient Greeks to the Scientific Revolution, Third Edition. University of Toronto Press. ISBN 978-1-4426-3503-6.

- Emsley, J. (2011). Nature's Building Blocks: An A-Z Guide to the Elements. Oxford University Press. ISBN 978-0-19-960563-7.

- Eschnaver, H. R.; Stoeppler, M. (1992). "Wine-An enological specimen bank". In Stoeppler, M. Hazardous Materials in the Environment. Elsevier Science. pp. 49-72 (58). doi:10.1016/s0167-9244(08)70103-3. ISBN 978-0444-89078-8.

- Evans, J. W. (1908). "V.- The meanings and synonyms of plumbago". Transactions of the Philological Society 26 (2): 133-79. doi:10.1111/j.1467968X.1908.tb00513.x.

- Finger, S. (2006). Doctor Franklin's Medicine. University of Pennsylvania Press. ISBN 978-0-8122-3913-3.

- Fiorini, E. (2010) (PDF). 2.000 years-old Roman Lead for physics. ASPERA. pp. 7-8. Retrieved 29 October 2016.

- Frankenburg, F. R. (2014). Brain-Robbers: How Alcohol, Cocaine, Nicotine, and Opiates Have Changed Human History. ABC-CLIO. ISBN 978-1-44082932-1.

- Frebel, A. (2015). Searching for the Oldest Stars: Ancient Relics from the Early Universe. Princeton University. ISBN 978-0-691-16506-6.

- Freeman, K. S. (2012). "Remediating soil lead with fishbones". Environmental Health Perspectives 120 (1): a20-a21. doi:10.1289/ehp.120a20a. PMID 22214821. PMC 3261960.

- Funke, K. (2013). "Solid State Ionics: from Michael Faraday to green energy-the European dimension". Science and Technology of Advanced Materials 14 (4): 1-50. doi:10.1088/1468-6996/14/4/043502.

- Gale, W. F.; Totemeier, T. C. (2003). Smithells Metals Reference Book. Butterworth-Heinemann. ISBN 978-0-08-048096-1.

- Gilfillan, S. C. (1965). "Lead poisoning and the fall of Rome". Journal of Occupational Medicine 7 (2): 53-60. ISSN 0096-1736. PMID 14261844

- Gill, T.; Libraries Board of South Australia (1974). The history and topography of Glen Osmond, with map and illustrations. Libraries Board of South Australia.

- Graedel, T. E.; et al. (2010). Metal stocks in Society - Scientific Synthesis (PDF) (Report). International Resource Panel. p. 17. ISBN 978-92-8073082-1. Retrieved 18 April 2017

- Grandjean, P. (1978). "Widening perspectives of lead toxicity". Environmental Research 17 (2): 303-21. doi:10.1016/0013-9351(78)900336. PMID 400972

- Greenwood, N. N.; Earnshaw, A. (1998). Chemistry of the Elements (2nd ed.). Butterworth-Heinemann. ISBN 978-0-7506-3365-9.

- Grout, J. (2017). "Lead poisoning and Rome". Encyclopaedia Romana. Retrieved 15 February 2017.

- Guberman, D. E. (2016). "Lead". 2014 Minerals Yearbook (PDF)(Report). United States Geological Survey. Retrieved 8 May 2017.

- Gulbinska, M. K. (2014). Lithium-ion Battery Materials and Engineering: Current Topics and Problems from the Manufacturing Perspective. Springer. p. 96. ISBN 978-1-4471-6548-4.

- Guruswamy, S. (2000). Engineering properties and applications of lead alloys. Marcel Dekker. ISBN 978-0-8247-8247-4.
- Hadlington, T. J. (2017). On the Catalytic Efficacy of Low-Oxidation State Group 14 Complexes. Springer. ISBN 978-3-319-51807-7.

- Harbison, R. D.; Bourgeois, M. M.; Johnson, G. T. (2015). Hamilton and Hardy's Industrial Toxicology. John Wiley \& Sons. ISBN 978-0-470-92973-5.

- Hauser, P. C. (2017). "Analytical Methods for the Determination of Lead in the Environment". In Astrid, S.; Helmut, S.; Sigel, R. K. O. Lead: Its Effects on Environment and Health. Metal Ions in Life Sciences. 17. de Gruyter. doi:10.1515/9783110434330-003.

- Hernberg, S. (2000). "Lead Poisoning in a Historical Perspective" (PDF). American Journal of Industrial Medicine 38(3): 244-54. doi:10.1002/10970274(200009)38:3<244::AID-AJIM3>3.0.CO;2-F. PMID 10940962. Retrieved 1 March 2017.

- "A History of Cosmetics from Ancient Times". Cosmetics Info. Retrieved 18 July 2016.

- Hodge, T. A. (1981). "Vitruvius, lead pipes and lead poisoning". American Journal of Archaeology (Archaeological Institute of America) 85 (4): 48691. doi:10.2307/504874.

- Hong, S.; Candelone, J.-P.; Patterson, C. C. et al. (1994). "Greenland ice evidence of hemispheric lead pollution two millennia ago by Greek and Roman civilizations" (PDF). Science 265 (5180): 1841-43. doi:10.1126/science.265.5180.1841. PMID 17797222.

- Hunt, A. (2014). Dictionary of Chemistry. Routledge. ISBN 978-1-13594178-9.

- IAEA - Nuclear Data Section (2017). "Livechart - Table of Nuclides - Nuclear structure and decay data". www-nds.iaea.org. International Atomic Energy Agency. Retrieved 31 March 2017.

- Insight Explorer; IPEN (2016). New Study Finds Lead Levels in a Majority of Paints Exceed Chinese Regulation and Should Not be on Store Shelves (PDF) (Report). Retrieved 3 May 2018

- Jensen, C. F. (2013). Online Location of Faults on AC Cables in Underground Transmission. Springer. ISBN 978-3-319-05397-4.

- Jones, P. A. (2014). Jedburgh Justice and Kentish Fire: The Origins of English in Ten Phrases and Expressions. Constable. ISBN 978-1-47211-389-4.

- Kaupp, M. (2014). "Chemical bonding of main-group elements". In Frenking, G.i Shaik, S. The Chemical Bond: Chemical Bonding Across the Periodic Table (PDF). John Wiley \& Sons. doi:10.1002/9783527664658.ch1.

- Kellett, C. (2012). Poison and Poisoning: A Compendium of Cases, Catastrophes and Crimes. Accent Press. ISBN 978-1-909335-05-9.

- King, R. B. (1995). Inorganic Chemistry of Main Group Elements. VCH Publishers. ISBN 978-1-56081-679-9.

- Konu, J.; Chivers, T. (2011). "Stable Radicals of the Heavy p-Block Elements". In Hicks, R. G. Stable Radicals: Fundamentals and Applied Aspects of Odd-Electron Compounds. John Wiley \& Sons. doi:10.1002/9780470666975.ch10. ISBN 978-0-470-77083-2.

- Kosnett, M. J. (2006). "Lead". In Olson, K. R. Poisoning and Drug Overdose (5th ed.). McGraw-Hill Professional. p. 238. ISBN 978-0-07-144333-3.

- Krestovnikoff, M.; Halls, M. (2006). Scuba Diving. Dorling Kindersley. ISBN 978-0-7566-4063-7.

- Kroonen, G. (2013). Etymological Dictionary of Proto-Germanic. Leiden Indo-European Etymological Dictionary Series. 11. Brill. ISBN 978-90-0418340-7.

- Langmuir, C. H.; Broecker, W. S. (2012). How to Build a Habitable Planet: The Story of Earth from the Big Bang to Humankind. Princeton University Press. ISBN 978-0-691-14006-3.

- Lauwerys, R. R.; Hoet, P. (2001). Industrial Chemical Exposure: Guidelines for Biological Monitoring, Third Edition. CRC Press. ISBN 978-1-4822-93838.

- Layton, M. (2017). "Lead faces threat of new Euro ban". shootinguk.co.uk. Retrieved 30 May 2018.

- "Lead sling bullet; almond shape; a winged thunderbolt on one side and on the other, in high relief, the inscription DEXAI "Catch!"'". The British Museum. Retrieved 30 April 2012.

- "Lead garden ornaments". H. Crowther Ltd. 2016. Retrieved 20 February 2017.

- "Lead in Waste Disposal". United States Environmental Protection Agency. 2016. Retrieved 28 February 2017.

- "Lead mining". The Northern Echo. Retrieved 16 February 2016.

- Levin, H. L. (2009). The Earth Through Time. John Wiley \& Sons. ISBN 9780-470-38774-0.

- Levin, R.; Brown, M. J.; Kashtock, M. E. et al. (2008). "Lead exposures in U.S. children, 2008: Implications for prevention". Environmental Health Perspectives 116 (10): 1285-93. doi:10.1289/ehp.11241. PMID 18941567. PMC 2569084.

- Lewis, J. (1985). "Lead Poisoning: A Historical Perspective". EPA Journal (United States Environmental Protection Agency) 11(4). Retrieved 31 January 2017. 
- Lide, D. R., ed. (2005). CRC Handbook of Chemistry and Physics(85th ed.). CRC Press. ISBN 978-0-8493-0484-2.

- Liu, J.; Liu, X.; Pak, V. et al. (2015). "Early blood lead levels and sleep disturbance in preadolescence". Sleep 38 (12): 1869-74. doi:10.5665/sleep.5230. PMID 26194570. PMC 4667382

- Lochner, J. C.; Rohrbach, G.; Cochrane, K. (2005). "What is Your Cosmic Connection to the Elements?" (PDF). Goddard Space Flight Center. Archived from the original (PDF) on 29 December 2016. Retrieved 2 July 2017.

- Lodders, K. (2003). "Solar System abundances and condensation temperatures of the elements" (PDF). The Astrophysical Journal 591 (2): 1220-47. doi:10.1086/375492. ISSN 0004-637X.

- Luckey, T. D.; Venugopal, B. (1979). Physiologic and Chemical Basis for Metal Toxicity. Plenum Press. ISBN 978-1-4684-2952-7.

- Macintyre, J. E. (1992). Dictionary of Inorganic Compounds. CRC Press. ISBN 978-0-412-30120-9.

- Marcillac, P. de; Coron, N.; Dambier, G. et al. (2003). "Experimental detection of ?-particles from the radioactive decay of natural bismuth". Nature 422 (6934): 876-78. doi:10.1038/nature01541. PMID 12712201.

- Marino, P. E.; Landrigan, P. J.; Graef, J. et al. (1990). "A case report of lead paint poisoning during renovation of a Victorian farmhouse". American Journal of Public Health 80 (10): 1183-85. doi:10.2105/AJPH.80.10.1183. PMID 2119148. PMC 1404824.

- Markowitz, G.; Rosner, D. (2000). "'Cater to the children": the role of the lead industry in a public health tragedy, 1900-55". American Journal of Public Health 90: 36-46. doi:10.2105/ajph.90.1.36. PMID 10630135. PMC 1446124.

- Masters, S. B.; Trevor, A. J.; Katzung, B. G. (2008). Katzung \& Trevor's Pharmacology: Examination \& Board Review (8th ed.). McGraw-Hill Medical. ISBN 978-0-07-148869-3.

- McCoy, S. (2017). "The End Of Lead? Federal Gov't Order Bans Sinkers, Ammo". GearJunkie. Retrieved 30 May 2018.

- Meija, J.; Coplen, T. B.; Berglund, M. et al. (2016). "Atomic weights of the elements 2013 (IUPAC Technical Report)". Pure and Applied Chemistry $\mathbf{8 8}$ (3): 265-291. doi:10.1515/pac-2015-0305.

- Merriam-Webster. "Definition of LEAD". www.merriam-webster.com. Retrieved 12 August 2016.

- Moore, M. R. (1977). "Lead in drinking water in soft water areas-health hazards". Science of the Total Environment 7 (2): 109-15. doi:10.1016/00489697(77)90002-X. PMID 841299.

- More, A. F.; Spaulding, N. E.; Bohleber, P. et al. (2017). "Next-generation ice core technology reveals true minimum natural levels of lead $(\mathrm{Pb})$ in the atmosphere: Insights from the Black Death". GeoHealth 1 (4): 211-219. doi:10.1002/2017GH000064. ISSN 2471-1403.

- Mosseri, S.; Henglein, A.; Janata, E. (1990). "Trivalent lead as an intermediate in the oxidation of lead(II) and the reduction of lead(IV) species". Journal of Physical Chemistry 94 (6): 2722-26. doi:10.1021/j100369a089.

- Mycyk, M.; Hryhorczuk, D.; Amitai, Y.; et al. (2005). "Lead". In Erickson, T. B.; Ahrens, W. R.; Aks, S. Pediatric Toxicology: Diagnosis and Management of the Poisoned Child. McGraw-Hill Professional. ISBN 978-0-07-141736-5.

- Nakashima, T.; Hayashi, H.; Tashiro, H. et al. (1998). "Gender and hierarchical differences in lead-contaminated Japanese bone from the Edo period". Journal of Occupational Health 40 (1): 55-60. doi:10.1539/joh.40.55.

- National Council on Radiation Protection and Measurements(2004). Structural Shielding Design for Medical X-ray Imaging Facilities. ISBN 978-0929600-83-3.

- National Institute for Occupational Safety and Health. "NIOSH Pocket Guide to Chemical Hazards - Lead". www.cdc.gov. Retrieved 18 November 2016

- Navas-Acien, A. (2007). "Lead Exposure and Cardiovascular Disease-A Systematic Review". Environmental Health Perspectives 115 (3): 472-482. doi:10.1289/ehp.9785. PMID 17431501. PMC 1849948.

- Nikolayev, S., ed. (2012). "*|Audh-". Indo-European Etymology. starling.rinet.ru. Retrieved 21 August 2016.

- Norman, N. C. (1996). Periodicity and the s-and p-Block Elements. Oxford University Press. ISBN 978-0-19-855961-0

- Nriagu, J. O. (1983). "Saturnine gout among Roman aristocrats - Did lead poisoning contribute to the fall of the Empire?". The New England Journal of Medicine 308 (11): 660-63. doi:10.1056/NEJM198303173081123. PMID 6338384.

- Nriagu, J. O.; Kim, M-J. (2000). "Emissions of lead and zinc from candles with metal-core wicks". Science of the Total Environment250 (1-3): 37-41. doi:10.1016/S0048-9697(00)00359-4. PMID 10811249.
- Occupational Safety and Health Administration. "Substance data sheet for occupational exposure to lead". www.osha.gov. Archived from the original on 16 March 2018. Retrieved 1 July2017.

- Olinsky-Paul, T. (2013). "East Penn and Ecoult battery installation case study webinar" (PDF). Clean Energy States Alliance. Retrieved 28 February 2017.

- Palmieri, R., ed. (2006). The Organ. Psychology Press. ISBN 978-0-41594174-7.

- "surma". Oxford English Dictionary (2nd). (2009). Oxford University Press.

- Park, J. H.; Bolan, N.; Meghara, M. et al. (2011). "Bacterial-assisted immobilization of lead in soils: Implications for remediation" (PDF). Pedologist: 162-74.

- Parker, R. B. (2005). The New Cold-Molded Boatbuilding: From Lofting to Launching. WoodenBoat Books. ISBN 978-0-937822-89-0.

- Parthe, E. (1964). Crystal Chemistry of Tetrahedral Structures. CRC Press. ISBN 978-0-677-00700-7.

- Pauling, L. (1947). General Chemistry. W. H. Freeman and Company. ISBN 978-0-486-65622-9.

- Peneva, S. K.; Djuneva, K. D.; Tsukeva, E. A. (1981). "RHEED study of the initial stages of crystallization and oxidation of lead and tin". Journal of Crystal Growth 53 (2): 382-396. doi:10.1016/0022-0248(81)90088-9. ISSN 00220248.

- Petzel, S.; Juuti, M.; Sugimoto, Yu. (2004). "Environmental Stewardship with Regional Perspectives and Drivers of the Lead-free Issue". In Puttlitz, K. J.; Stalter, K. A. Handbook of Lead-Free Solder Technology for Microelectronic Assemblies. CRC Press. ISBN 978-0-8247-5249-1.

- Polyanskiy, N. G. (1986). Fillipova, N. A, ed. Аналитическая химия элементов: Свинец [Analytical Chemistry of the Elements: Lead] (in Russian). Nauka.

- Prasad, P. J. (2010). Conceptual Pharmacology. Universities Press. ISBN 978-81-7371-679-9. Retrieved 21 June 2012.

- "Primary Lead Refining Technical Notes". LDA International. Archived from the original on 22 March 2007. Retrieved 7 April2007.

- Progressive Dynamics, Inc. "How Lead Acid Batteries Work: Battery Basics". progressivedyn.com. Retrieved 3 July 2016.

- Putnam, B. (2003). The Sculptor's Way: A Guide to Modelling and Sculpture. Dover Publications. ISBN 978-0-486-42313-5.

- Pyykko, P. (1988). "Relativistic effects in structural chemistry". Chemical Reviews 88 (3): 563-94. doi:10.1021/cr00085a006.

- Rabinowitz, M. B. (1995). "Imputing lead sources from blood lead isotope ratios". In Beard, M. E.; Allen Iske, S. D. Lead in Paint, Soil, and Dust: Health Risks, Exposure Studies, Control Measures, Measurement Methods, and Quality Assurance. ASTM. pp. 63-75. doi:10.1520/stp12967s. ISBN 978-08031-1884-3.

- Ramage, C. K., ed. (1980). Lyman Cast Bullet Handbook (3rd ed.). Lyman Products Corporation.

- Randerson, J. (2002). "Candle pollution". New Scientist (2348). Retrieved 7 April 2007.

- Reddy, A.; Braun, C. L. (2010). "Lead and the Romans". Journal of Chemical Education 87 (10): 1052-55. doi:10.1021/ed100631y.

- Retief, F.; Cilliers, L. P. (2006). "Lead poisoning in ancient Rome". Acta Theologica 26 (2): 147-64 (149-51). doi:10.4314/actat.v26i2.52570.

- Rich, V. (1994). The International Lead Trade. Woodhead Publishing. ISBN 978-0-85709-994-5.

- Rieuwerts, J. (2015). The Elements of Environmental Pollution. Routledge. ISBN 978-0-415-85919-6.

- Riva, M. A.; Lafranconi, A.; d'Orso, M. I. et al. (2012). "Lead poisoning: Historical aspects of a paradigmatic "occupational and environmental disease"'.". Safety and Health at Work 3 (1): 11-16. doi:10.5491/SHAW.2012.3.1.11. PMID 22953225. PMC 3430923.

- Roederer, I. U.; Kratz, K.-L.; Frebel, A. et al. (2009). "The end of nucleosynthesis: Production of lead and thorium in the early galaxy". The Astrophysical Journal (The American Astronomical Society) 698 (2): 196380. doi:10.1088/0004-637X/698/2/1963. Retrieved 18 July 2016.

- Rogalski, A. (2010). Infrared Detectors (2nd ed.). CRC Press. ISBN 978-14200-7671-4. Retrieved 19 November 2016.

- Rohr, C. (2017). "Binare Zintl-Phasen" [Binary Zintl Phases]. Intermetallische Phasen [Intermettallic Phases] (in German). Universitat Freiburg. Retrieved 18 February 2017

- Rudolph, A. M.; Rudolph, C. D.; Hostetter, M. K.; et al. (2003). "Lead". Rudolph's Pediatrics (21st ed.). McGraw-Hill Professional. p. 369. ISBN 9780-8385-8285-5.

- Samson, G. W. (1885). The divine law as to wines. J. B. Lippincott \& Co.

- Scarborough, J. (1984). "The myth of lead poisoning among the Romans: An essay review". Journal of the History of Medicine and Allied Sciences 39 (4): 469-475. doi:10.1093/jhmas/39.4.469. PMID 6389691. 
- Schoch, R. M. (1996). Case Studies in Environmental Science. West Publishing. ISBN 978-0-314-20397-7.

- Schoeters, G.; Den Hond, E.; Dhooge, W. et al. (2008). "Endocrine disruptors and abnormalities of pubertal development". Basic \& Clinical Pharmacology \& Toxicology 102 (2): 168-175. doi:10.1111/j.17427843.2007.00180.x. PMID 18226071.

- Sharma, H. R.; Nozawa, K.; Smerdon, J. A. et al. (2013). "Templated threedimensional growth of quasicrystalline lead". Nature Communications 4: 2715. doi:10.1038/ncomms3715.

- Sharma, H. R.; Smerdon, J. A.; Nugent, P. J. et al. (2014). "Crystalline and quasicrystalline allotropes of $\mathrm{Pb}$ formed on the fivefold surface of icosahedral Ag-In-Yb". The Journal of Chemical Physics 140: 174710. doi:10.1063/1.4873596

- Silverman, M. S. (1966). "High-pressure (70-k) synthesis of new crystalline lead dichalcogenides". Inorganic Chemistry 5 (11): 2067-69. doi:10.1021/ic50045a056.

- Singh, P. (2017). "Over 73\% of paints found to have excessive lead: Study". w:Times of India. Retrieved 3 May 2018.

- Sinha, S. P.; Shelly; Sharma, V. et al. (1993). "Neurotoxic effects of lead exposure among printing press workers". Bulletin of Environmental Contamination and Toxicology 51 (4): 490-93. doi:10.1007/BF00192162.

- Slater, J. C. (1964). "Atomic Radii in Crystals". The Journal of Chemical Physics 41 (10): 3199-3204. doi:10.1063/1.1725697. ISSN 0021-9606.

- Smirnov, A. Yu.; Borisevich, V. D.; Sulaberidze, A. (2012). "Evaluation of specific cost of obtainment of lead-208 isotope by gas centrifuges using various raw materials". Theoretical Foundations of Chemical Engineering 46 (4): 373-78. doi:10.1134/s0040579512040161.

- Sokol, R. C. (2005). "Lead exposure and its effects on the reproductive system". In Golub, M. S. Metals, Fertility, and Reproductive Toxicity. CRC Press. pp. 117-53. doi:10.1201/9781420023282.ch6. ISBN 978-0-41570040-5.

- Stabenow, F.; Saak, W.; Weidenbruch, M. (2003). "Tris(triphenylplumbyl) plumbate: An anion with three stretched lead-lead bonds". Chemical Communications (18): 2342-2343. doi:10.1039/B305217F.

- Stone, R. (1997). "An Element of Stability". Science 278 (5338). doi:10.1126/science.278.5338.571.

- Street, A.; Alexander, W. (1998). Metals in the Service of Man(11th ed.). Penguin Books. ISBN 978-0-14-025776-2.

- Szczepanowska, H. M. (2013). Conservation of Cultural Heritage: Key Principles and Approaches. Routledge. ISBN 978-0-415-67474-4.

- Takahashi, K.; Boyd, R. N.; Mathews, G. J. et al. (1987). "Bound-state beta decay of highly ionized atoms" (PDF). Physical Review C (American Institute of Physics for the American Physical Society) 36 (4). doi:10.1103/physrevc.36.1522. OCLC 1639677. Retrieved 27 August 2013.

- Tarrago, A. (2012). "Case Studies in Environmental Medicine (CSEM) Lead Toxicity" (PDF). Agency for Toxic Substances and Disease Registry.

- Tetreault, J.; Sirois, J.; Stamatopoulou, E. (1998). "Studies of lead corrosion in acetic acid environments". Studies in Conservation 43(1): 1732. doi:10.2307/1506633.

- "Think Lead research summary" (PDF). The Lead Sheet Association. Retrieved 20 February 2017.

- Thomson, T. (1830). The History of Chemistry. Henry Colburn and Richard Bentley (publishers).

- Thornton, I.; Rautiu, R.; Brush, S. M. (2001). Lead: The Facts(PDF). International Lead Association. ISBN 978-0-9542496-0-1. Retrieved 5 February 2017.

- Thurmer, K.; Williams, E.; Reutt-Robey, J. (2002). "Autocatalytic oxidation of lead crystallite surfaces". Science 297 (5589): 2033-35. doi:10.1126/science.297.5589.2033. PMID 12242437.

- Tolliday, B. (2014). "Significant growth in lead usage underlines its importance to the global economy". International Lead Association. Retrieved 28 February 2017. Global demand for lead has more than doubled since the early 1990 s and almost $90 \%$ of use is now in lead-acid batteries

- "Toronto museum explores history of contraceptives". ABC News. 2003. Retrieved 13 February 2016.

- "Toxic Substances Portal - Lead". Agency for Toxic Substances and Disease Registry. Archived from the original on 6 June 2011.

- "Toxicological Profile for Lead" (PDF). Agency for Toxic Substances and Disease Registry/Division of Toxicology and Environmental Medicine. 2007. Archived from the original (PDF)on 2 July 2017.

- "Trace element emission from coal". IEA Clean Coal Centre. 2012. Retrieved 1 March 2017.

- Tucek, K.; Carlsson, J.; Wider, H. (2006). "Comparison of sodium and leadcooled fast reactors regarding reactor physics aspects, severe safety and economical issues" (PDF). Nuclear Engineering and Design 236 (14-16): 1589-98. doi:10.1016/j.nucengdes.2006.04.019.

- Tungate, M. (2011). Branded Beauty: How Marketing Changed the Way We Look. Kogan Page Publishers. ISBN 978-0-7494-6182-9.

- UK Marine SACs Project (1999). "Lead". Water Quality (Report). Retrieved 10 June 2018.

- United Nations Environment Programme (2010). Final review of scientific information on lead (PDF). Chemicals Branch, Division of Technology, Industry and Economics. Retrieved 31 January2017.

- United States Environmental Protection Agency (2010). "Metallurgical Industry:Secondary Lead Processing". AP 42 Compilation of Air Pollutant Emission Factors (5th ed.). Retrieved 20 May 2018.

- United States Environmental Protection Agency (2000). "Regulatory Status of Waste Generated by Contractors and Residents from Lead-Based Paint Activities Conducted in Households (August 2000)". Retrieved 28 February 2017.

- United States Environmental Protection Agency (2005). "Best Management Practices for Lead at Outdoor Shooting Ranges"(PDF). Retrieved 12 June 2018.

- United States Food and Drug Administration (2015). Q3D Elemental Impurities Guidance for Industry (PDF) (Report). United States Department of Health and Human Services. p. 41. Retrieved 15 February 2017.

- United States Geological Survey (1973). Geological Survey Professional Paper. United States Government Publishing Office. p. 314.

- United States Geological Survey (2005). Lead (PDF) (Report). Retrieved 20 February 2016.

- United States Geological Survey (2017). "Lead" (PDF). Mineral Commodities Summaries. Retrieved 8 May 2017

- University of California Nuclear Forensic Search Project. "Decay Chains". Nuclear Forensics: A Scientific Search Problem. Retrieved 23 November 2015.

- Vasmer, M. (1986-1987) [1950-1958]. Trubachyov, O. N.; Larin, B. O., eds. Этимологический словарь русского языка[Russisches etymologisches Worterbuch] (in Russian) (2nd ed.). Progress. Retrieved 4 March 2017.

- Vogel, N. A.; Achilles, R. (2013). The Preservation and Repair of Historic Stained and Leaded Glass (PDF) (Report). United States Department of the Interior. Retrieved 30 October 2016.

- Waldron, H. A. (1985). "Lead and lead poisoning in antiquity". Medical History 29 (1): 107-08. doi:10.1017/S0025727300043878. PMC 1139494.

- Wani, A. L.; Ara, A.; Usman, J. A. (2015). "Lead toxicity: A review" (PDF). Interdisciplinary Toxicology 8 (2). doi:10.1515/intox-2015-0009. PMID 27486361. PMC 4961898

- Weast, R. C.; Astle, M. J.; Beyer, W. H. (1983). CRC Handbook of Chemistry and Physics: A Ready-reference Book of Chemical and Physical Data. CRC Press. ISBN 978-0-8493-0464-4.

- "Weatherings to Parapets and Cornices". The Lead Sheet Association. Retrieved 20 February 2017.

- Webb, G. A. (2000). Nuclear Magnetic Resonance. Royal Society of Chemistry. ISBN 978-0-85404-327-9.

- Webb, G. W.; Marsiglio, F.; Hirsch, J. E. (2015). "Superconductivity in the elements, alloys and simple compounds". Physica C: Superconductivity and its Applications 514: 17-27. doi:10.1016/j.physc.2015.02.037.

- Whitten, K. W.; Gailey, K. D.; David, R. E. (1996). General chemistry with qualitative analysis (3rd ed.). Saunders College. ISBN 978-0-03-012864-6.

- Wiberg, E.; Wiberg, N.; Holleman, A. F. (2001). Inorganic Chemistry. Academic Press. ISBN 978-0-12-352651-9.

- Wilkes, C. E.; Summers, J. W.; Daniels, C. A.; et al. (2005). PVC Handbook. Hanser. ISBN 978-1-56990-379-7.

- Willey, D. G. (1999). "The physics behind four amazing demonstrations CSI". Skeptical Inquirer 23 (6). Retrieved 6 September 2016.

- Winder, C. (1993a). "The history of lead - Part 1". LEAD Action News. The LEAD Group. ISSN 1324-6011. Archived from the original on 31 August 2007. Retrieved 5 February 2016.

- Winder, C. (1993b). "The history of lead - Part 3". LEAD Action News 2 (3). ISSN 1324-6011. Archived from the original on 31 August 2007. Retrieved 12 February 2016.

- Windholz, M. (1976). Merck Index of Chemicals and Drugs (9th ed.). Merck \& Co. ISBN 978-0-911910-26-1. Monograph 8393.

- World Health Organization (1995). Environmental Health Criteria 165: Inorganic Lead (Report). Retrieved 10 June 2018.

- World Health Organization (2000). "Lead". Air quality guidelines for Europe (PDF). Regional Office for Europe. pp. 149-53. ISBN 978-92-890-1358-1. OCLC 475274390.

- World Nuclear Association (2015). "Nuclear Radiation and Health Effects". Retrieved 12 November 2015 
- Wrackmeyer, B.; Horchler, K. (1990). "207Pb-NMR Parameters". Annual Reports on NMR Spectroscopy (Academic Press) 22: 249-303. ISBN 978-008-058405-8.

- Yong, L.; Hoffmann, S. D.; Fassler, T. F. (2006). "A low-dimensional arrangement of $\left[\mathrm{Pb}_{9}\right]^{4}$ ? clusters in $\left[\mathrm{K}(18 \text {-crown-6) }]_{2} \mathrm{~K}_{2} \mathrm{~Pb}_{9} \text {.(en) }\right)_{1.5}$ ". Inorganica Chimica Acta (Elsevier) 359 (15): 4774-78. doi:10.1016/j.ica.2006.04.017.

- Young, S. (2012). "Battling lead contamination, one fish bone at a time". Compass. United States Coast Guard. Retrieved 11 February 2017.

- Yu, L.; Yu, H. (2004). Chinese Coins: Money in History and Society. Long River Press. ISBN 978-1-59265-017-0.

- Zhang, X.; Yang, L.; Li, Y. et al. (2012). "Impacts of lead/zinc mining and smelting on the environment and human health in China". Environmental Monitoring and Assessment 184 (4): 2261-73. doi:10.1007/s10661-0112115-6. PMID 21573711.

- Zhao, F. (2008). Information Technology Entrepreneurship and Innovation. IGI Global. p. 440. ISBN 978-1-59904-902-1.
- Zuckerman, J. J.; Hagen, A. P. (1989). Inorganic Reactions and Methods, the Formation of Bonds to Halogens. John Wiley \& Sons. ISBN 978-0-47118656-4.

- Zweifel, H. (2009). Plastics Additives Handbook. Hanser. ISBN 978-3-44640801-2.

- Zyka, J. (1966). "Analytical study of the basic properties of lead tetraacetate as oxidizing agent". Pure and Applied Chemistry 13(4): 569-81. doi:10.1351/pac196613040569. Retrieved 2 March 2017.

\section{Further reading}

- Astrid, S.; Helmut, S.; Sigel, R. K. O., eds. (2017). Lead: Its Effects on Environment and Health. Metal lons in Life Sciences. 17. De Gruyter. ISBN 978-3-11-044107-9. Table of contents

- Casas, J. S.; Sordo, J., eds. (2006). Lead Chemistry, Analytical Aspects. Environmental Impacts and Health Effects. Elsevier. ISBN 978-0-44452945-9. 